\title{
Expectations and Projections for the Future of Nongynecolgical Cytology 10 Years Ago: Did They Materialize and How Did We Do?
}

\author{
Fernando C. Schmittt ${ }^{\mathrm{a}, \mathrm{b}}$ Philippe Vielh ${ }^{\mathrm{c}}$

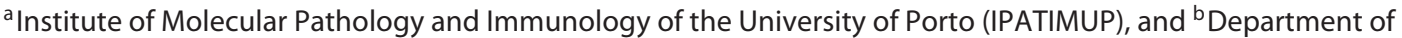 \\ Pathology and Oncology, Medical Faculty, University of Porto, Porto, Portugal; ' CLaboratoire National de Santé, \\ Dudelange, Luxembourg
}

\section{Keywords}

Nongynecologic cytology · Fine-needle aspiration .

Immunocytochemistry · Molecular techniques

\begin{abstract}
In 2007, an article entitled "How Technology Is Reshaping the Practice of Nongynecologic Cytology: Frontiers of Cytology Symposium" [Bibbo: Acta Cytol 2007;51:123-152] was published. The moderator and editor was Marluce Bibbo, previous Editor-in-Chief of Acta Cytologica, and 17 participants from countries throughout the world were asked to answer how new technologies were being applied in their respective laboratories and whether future advances and challenges can be predicted. Ten years later, two previous participants in this Golden Anniversary Cytology Symposium were asked by Kari Syrjänen, current Editor-in-Chief of Acta Cytologica, to make a reappraisal of the 2007 predictions.

(c) 2017 S. Karger AG, Basel
\end{abstract}

It is a great privilege for us to write the commentary on this article, published 10 years ago for the Golden Anniversary of Acta Cytologica, and of which we were coau- thors [1]. Having a visionary idea, Dr. Marluce Bibbo, Editor-in-Chief of the journal at that time, invited $17 \mathrm{cy}$ topathologists and cytotechnologists, from 12 countries and representing 4 continents, to discuss how new technology is being applied and what advances and challenges we are predicting for the future. Ten years on, and to celebrate 60 Years of Acta Cytologica, Dr. Kari Syrjänen, the current Editor-in-Chief, presented us with the challenge of describing the impact of this article in the development of our specialty as well as in the increase of knowledge at a conceptual level [2].

There were several ways to present this discussion, but we decided to do it according to the different questions originally formulated in the article, and to then verify if the expectations and projections made at that time are still of interest, have changed, or are no longer in place. We also comment on some of the new developments in the technology and the biomarkers that were not predicted at that time but are now implemented in most pathology laboratories.

1. The Role of Morphology. For several decades, cytopathologists have practiced diagnostic cytopathology of nongynecologic specimens based on morphologic features. Do you think morphologic features will still play an important role 10 years from now?

\section{KARGER}

() 2017 S. Karger AG, Basel

E-Mail karger@karger.com

www.karger.com/acy
Correspondence to: Prof. Fernando C. Schmitt 
All the participants predicted that morphology would still play an important role 10 years later. They were, indeed, completely right. In 2017, morphology still is the cornerstone for diagnosis in cytopathology and, even with the huge advances in molecular genetics in the last decade, the success of these latter techniques depends on a good qualitative and quantitative evaluation of the cytologic material [3].

2. The Role of Imaging Techniques. Fine-needle aspiration (FNA) under the guidance of several imaging techniques has become an indispensable component of the workup of many lesions. The issues discussed under this topic were: Who performs FNA? What is the role of core biopsy? Can the imaging techniques replace cytology in the diagnosis?

Practice in this field is consolidated after 10 years. Guided FNA is usually performed by radiologists, and interventional radiology has grown exponentially during the last decade. Pathologists, clinicians, and surgeons still perform aspirations, mainly with the use of ultrasound guidance. One field that has expanded significantly is the cytomorphology of endobronchial ultrasound (EBUS)guided FNA that allows for material to be obtained from the lung and mediastinal lymph nodes for the diagnosis and staging of lung (and other) cancer. This creates new opportunities for cytology, especially with the practice of rapid on-site evaluation (ROSE) to verify the quality of the material, thereby facilitating the collection of proper material for ancillary techniques. The role of core-biopsy is still the same in breast, prostate, liver, and soft-tissue tumors, among others. In many situations, this methodology complements FNA. As was predicted at the time, no imaging technique is able to replace morphological diagnosis in 2017.

3. The Role of Immunocytochemistry. Immunocytochemistry (ICC) has become an important adjunct for cytological diagnosis; however, the use of different preparations and fixation were a problem for standardization. Questions about the current and future roles of this technique and the challenges were discussed.

All the authors agreed that the major challenge would be to standardize ICC within and across laboratories. Despite efforts being made and collaborative studies [4] as well as significant improvements in the technique with automation and better quality control, we still do not have universal standardization for the application of ICC techniques in cytological material. This is understandable, particularly because when we deal with such material we talk about a series of different types of preparations: smears fixed in alcohol, air-dried smears, liquid-based cy- tology, cell blocks, etc. Since most laboratories perform the technique of immunodetection in paraffin-embedded blocks like 10 years ago, ICC is usually carried out from cell block material. Most of the diagnostic and prognostic applications of ICC described in the article are still being used [1]. However, it is interesting to note that one of the markers that is extremely useful today for the subtyping of non-small-cell lung cancer, i.e., p40 [5], was not described at that time. Some of the panelists predicted that ICC would be important to guide targeted therapies, but noone predicted the screening role of ICC for molecular techniques, e.g., in the use of ALK and ROS- 1 antibodies in order to select cases for searching translocations in these genes [6].

4. The Role of Clinical Cytogenetics. Clinical applications of fluorescence in situ hybridization (FISH) have been growing in the last decade.

Although some authors predicted the expansion of the use of FISH in this last decade, its use in cytology is, in fact, practically the same as 10 years ago. Indications for using the UroVysion kit in urinary cytology are still under debate [7] as well as its role in the diagnosis of effusions or pancreaticobiliary cytology. Like 10 years ago, it is still used for the detection of translocations in sarcomas and lymphomas, but is limited to some specialized centers. Interestingly, one of the most common uses of FISH in cytological labs nowadays, i.e., the search for ALK translocations in lung cancer, was not predicted at that time [ 1 , 6]. However, the prediction that FISH analysis would be fully automatized, with specialized fluorescence microscopes and multiple filters for multiprobe FISH becoming the norm, was not accurate, as it is not in regular use in nonhematological solid tumors.

5. The Role of Molecular Techniques. A variety of molecular assays for the detection of gene mutations, amplifications, and DNA instability have demonstrated clinical utility in cytology. The main topics discussed were the applications of these techniques, the question if target therapies boost the use of molecular techniques in cytology, and the prediction of advances and challenges in their implementation.

Curiously, one technique that is changing the paradigm of molecular genetics, i.e., next-generation sequencing, was not mentioned, and this is revolutionizing cancer genomics [10]. High-quality reference genome sequences provide us with the prospect of studying genetic variations on an unprecedented scale. Genes, genomic regions, and whole genomes can be resequenced and aligned to appropriate references, and genetic peculiarity between tumors and individuals can be detected. We can investi- 
gate cancer in terms of specific events, i.e., somatic basepair deletions and mutations, balanced and unbalanced rearrangements, and copy number changes, and we can discern cancer-specific genomic regions, genes, or exomes. Similar technology extends to RNA. We can explore the expression of genomic mutations, gene fusion events, posttranslational edits and alternative and novel splice events. This technology is rapidly replacing the classical use of polymerase chain reaction (PCR) or Sanger sequencing to detect alterations in individual genes. Ten years ago, the use of molecular techniques to detect mutations in EGFR in lung cancer, KRAS in colon cancer, and cKIT in GISTs was just starting. Genomic panels that allow the study of multiple genes at same time, with just $10 \mathrm{ng}$ of DNA, are perfect for cytology as only a small amount of material is available. As predicted by the authors in the original article, targeted therapy boosted by the use of molecular techniques in cytology and lung cytology is the best example. In almost half of lung cancers, the only material available for molecular studies that guide therapy is cytologic material. This changed the paradigm of using materials such as small biopsies and cytology samples managed for diagnostic purposes, while maximizing the amount of tissue available for molecular studies [11] for theragnostic applications. Another methodology implemented in recent years which was not predicted in the article was HPV detection in head and neck cancers that has now become a routine in many centers [12].

One of the most important discussions still deserving to be reflected upon today concerns the challenges for the implementation of molecular techniques in the routine of pathology labs. We would like to quote several sentences from the article [1] on matters that are still under discussion at present:

"It is important that we cytologists take an active role in the adoption and application of molecular techniques, since we are able to interpret the results in the light of cytomorphology. If we do not act, others will take over."

"The advance of molecular techniques poses two challenges for the cytology laboratory: deciding when to adopt a new test and deciding who should perform and interpret it."

"The cytology laboratory will likely find itself squeezed between rising expectations for advances in molecular medicine and the limitation imposed by good evidencebased practice and funding."

Ten years on, cytopathologists and pathologists, in general, still do not play an active role in the adoption and application of molecular techniques. There is no doubt

Expectations and Projections for

Nongynecological Cytology that many things have changed, and there are more pathologists involved in molecular pathology. However, there is a gap between the fast speed of implementation of these techniques and the relatively slow engagement of the pathologists. In some laboratories, it is possible to see pathologists working actively together with molecular biologists and scientists, deciding with them which new tests to implement and signing out the respective reports. Many tests used today are based on large and solid clinical trials and molecular tumor boards are a reality in some centers. Funding is still a problem, but since many tests are tailored to specific treatments, in many cases it is possible to demonstrate the financial advantages to implement certain tests.

Let's remember some other quotes:

"Because therapies are now being directed toward individual molecular targets, the big challenge for the use of cytologic technology is a need for increased standardization of preanalytical and analytical methods."

We raised the concerns with preanalytical issues some years ago, but this is still a problem in pathology in general, and specifically in cytology [13]. However, with the adoption of sophisticated technologies, this problem is increasingly being addressed and nowadays, more and more cytopathologists and cytotechnologists are becoming aware about the needs of a proper collection and preservation of the material as well as the need for the standardization of techniques $[3,14]$.

"In the future, most if not all tumor diagnoses will consist of a morphologic type with molecular subclassification."

This prediction is a reality in the clinical practice of some tumors. Breast cancer, lung cancer, central nervous system tumors, and lymphomas, besides the morphological classification, need a molecular classification obtained directly by molecular methods or by the use of surrogate ICC markers. This is fundamental for the correct management of these neoplasms and, in the near future, it will expand to other types of tumors.

"More organized and systematic molecular biology training is required in both undergraduate and postgraduate pathology education."

Seven years ago, 3 years after the publication of this discussion, one of us wrote an editorial in Acta Cytologica [15], calling the attention for the need of a better training of all cytologists with the aim of understanding the main principles and applications of molecular diagnosis. This is progressing, but too slowly. In some countries, molecular pathology is part of the training in pathology. In Portugal, all residents have an obligatory rotation in molecu- 
lar pathology: the period is short ( 2 months during the 5 years of training), but it is a beginning. In France, it is possible to obtain an academic diploma of molecular pathology ( 2 years), in place since 2011. Given the tremendous importance of the integration of molecular techniques in the specialty of pathology, we hope that the knowledge of pathologists in general, and cytopathologists in particular, will increase deeper and faster in the next few years.

As we wrote at the beginning of this commentary, it was a great pleasure for us to have the opportunity to re- vise the original article, and we hope that this review is pleasant reading. After 10 years, we can conclude, exactly as Dr. Bibbo concluded the original discussion [1]:

"Since molecular biology results are meaningful only when interpreted with proper morphologic correlation, it is important to standardize molecular techniques and organize education in molecular biology for pathologists."

\section{Disclosure Statement}

The authors have no conflicts of interest to declare. 


\title{
Golden ANNIVERSARY CYTOLOGY SYMPOSIUM
}

\section{How Technology Is Reshaping the Practice of Nongynecologic Cytology}

\section{Frontiers of Cytology Symposium}

\author{
Moderutor and Editor \\ Marluce Bibbo, M.D., Sc.D., F.A.S.C.P., F.I.A.C. \\ Participants \\ Måns Àkerman, M.D., Ph.D., F.I.A.C., Venancio A. F. Alves, M.D., Ph.D., Lukas Bubendorf, M.D., \\ M.I.A.C., Terence J. Colgan, M.D., F.R.C.P.C., F.C.A.P., M.I.A.C., Hitoshi Itoh, C.T.I.A.C., M.I.A.C., \\ Kusum Kapila, M.D., F.A.M.S., F.R.C.Path., F.I.A.C., Ruth L. Katz, M.D. M.I.A.C., Gerardine Mitchell, \\ B. App. Sc. (Medical Technology), A.S.C., M.A.I.M.S., Nicholas J. Mulvany, M.B., B.Ch., B.A.O., D.C.P., \\ F.I.A.C., F.R.C.P.A., Joseph F. Nasuti, M.D., F.C.A.P., F.A.S.C.P., Wai-Kuen Ng, M.B.B.S., F.R.C.P.A., \\ F.H.K.C.Path, F.H.K.A.M.(Pathology), F.I.A.C., Robert Y. Osamura, M.D., F.I.A.C., José P. Schalper, \\ M.D., M.I.A.C., Fernando Carlos Schmitt, M.D., Ph.D., F.I.A.C., Akihiko Serizawa, C.T.I.A.C.,
} Alain P. Verhest, M.D., Ph.D., F.I.A.C., and Philippe Vielh, M.D., Ph.D., M.I.A.C.

To pay tribute to the Founders of Acta Cytologica, this Golden Anniversary symposium on nongynecologic cytology revives the written symposium style of the 1950 s. Participants from countries throughout the world were asked bow new technologies are currently applied in their laboratories and whether future advances and challenges can be predicted. The specific questions and the participants' answers follow. (Acta Cytol 2007;51:123-152)

Keywords: nongynecologic cytology, FNA, guided FNA, core biopsy, imaging techniques, immunocytochemistry, clinical cytogenetics, FISH, CISH, molecular techniques.

\section{The Role of Morphology}

For several decades, cytopathologists bave practiced diagnostic cytopathology of nongynecologic specimens based on morphologic features.

\section{A. Do you think morphologic features will still play an important role 10 years from now?}

Dr. Akerman. Morphologic features will still play an important role 10 years from now. There are a number of entities in which diagnostic cytologic criteria have been defined, and the combined evaluation of clinical data and cytologic features are sufficient for definitive treatment. Nodular fasciitis is a typical ex-

This international symposium by correspondence was organized by Dr. Marluce Bibbo, Editor-in-Chief of Actn Cytnlogici, who invited the members and posed the questions. None of the members knew the identity of the other panel members at the time they responded to the questions. The identities of the panel inembers were discloset to each participant when proofs were mailed for corrections. Members of the panel are listed alphabetically and are well known to practicing cytopathologists.

Dr. Bibbo is The Warren R. Lang Professor of Pathology and Cell Biology and Director of Cytopathology, Departunent of Pathology, lefferson Medical College, Philadelphia, Pennsylvania, U.S.A. (marluce.bibbo@mail.tju.edu).

Dr. Akernan is Senior Cytopathologist and Associate Professor, Department of Pathology and Cytology, University Hospital, Lund, Sweden (mans.akernam@skane.se).

Dr. Alves is Professor of Pathology and Director of Anatomic Pathology and Cytopathology. São Paulo University School of Medicine, São Paulo, Brazil (venancio@uol.com.hr),

0001-5547/07/5102-0123/\$19.00/0 The International Academy of Cytology

ACTA CYTOLOGICA

123

Expectations and Projections for Nongynecological Cytology
Acta Cytologica 2017;61:373-407 DOI: $10.1159 / 000477713$ 


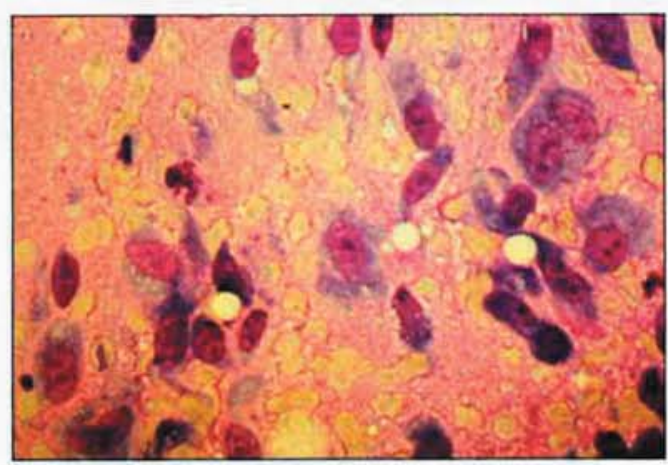

Figure 1 Young woman with a 2-week history of a growing, painful, 2-cm subcutaneous, tender tumor in the right forearm. In a myxoid background matrix, different-sized myofibroblasts, polyhedral and spindly with cytoplasmic extensions were found. Binucleated ganglion cell-like myofibroblasts were present. The clinical data together with the cytomorphology are typical for an early form of nodular fasciitis (May-Grünwaid-Giemsa stain, $\times 40$ ).

\section{ample $^{1}$ (Figure 1).}

Even if, 10 years from now, the final evaluation of a lesion is based mainly on ancillary techniques and not on morphology, the cytologic evaluation of a fine needle aspiration (FNA) sample is necessary to confirm that the sample is representative for the lesion in question.

Dr. Alves. I am absolutely confident that the practice of diagnostic cytopathology will continue to grow. Indeed, in these days of increasing globalization, the active presence of the cytopathologist in the multispecialty medical team will be critical for fast, safe preoperatory and intraoperatory diagnosis of nodular lesions.

Dr. Bubendorf. The growing importance of molecular analyses will not weaken but rather will strengthen the role of morphology. This will be particularly true for the diagnosis of malignant tumors. Given the fact that cytologic specimens are a variably balanced mixture of tumor cells and reactive cells, appropriate identification, selection or purification of tumor cells is crucial to application of molecular techniques. Molecular techniques can overcome diagnostic uncertainties and limitations in defined fields of cytology. However, cytology will hardly be challenged in the many fields where it provides a highly accurate diagnosis at a low cost. Diagnostic cytopathologists will be challenged as translators between morphology and molecular applications. This requires a tight collaboration between cytopathologist and molecular biologists. Cytopathologists must actively be involved and avoid leaving this emerging field to pure biologists with insufficient morphologic backup.

Dr. Kapila. Diagnostic cytopathology based on morphologic features will continue to be the anchor of diagnoses in FNA. Morphologic features would be the foundation for deciding the various ancillary techniques to be adopted to arrive at an accurate diagnosis. However, in nongynecologic exfoliative specimens morphology will play an important role, but in certain specimens such as urine cytology its role will be limited as an increasing number of nonmorphologic tests with higher sensitivity/specificity become available.

Dr. Katz. Morphology will always be the most important starting point for diagnosis and, in fact, may be used as a solo method of diagnosis in many cases.

Dr. Mulvany and Ms. Mitchell. Cytomorphologic features and molecular studies are mutually complementary. In the latter, false positive results may arise from erroneous target recognition or lack of appropriate controls. False negative results may be due to specimen sampling, variant target forms or technical shortcomings, including poor storage conditions or delayed preparation of samples. Thus there is a continuing necessity for correlation of cytomorphology, molecular results, medical history and clinical findings.

Dr. Bubendorf is Associate Professor, Institute for Pathology, University Hospital, Basel, Switzerland (lbubendo@bluewin.ch).

Dr. Colgan is Head of Gynaecological Pathology, Pathology and Laboratory Medicine, and Professor of Laboratory Medicine and Pathobiology, University of Toronto, Mount Sinai Hospital, Toronto, Ontario, Canada (tcolgan@mtsinai.on.ca).

Dr. Itoh is Cytotechnologist, Tokai University Hospital, Kangawa, Japan (itoh-cyt@is.icc.u-tokai.ac.jp).

Dr. Kapila is Professor of Pathology, Department of Pathology, Head of Cytopathology Unit, Faculty of Medicine, Kuwait University, Kuwait (kkapila@yahoo.com).

Dr. Katz is Professor of Pathology, Chief of Research Cytopathology and Director of Image Analysis, Department of Pathology, Univeristy of Texas M. D. Anderson Cancer Center, Houston, Texas, U.S.A. (rkatz@mdanderson.org).

Ms. Mitchell is Member ASC, MAJMS, and Senior Scientist, Cytology, Austin Hospital, Melbourne, Australia (geraldine.mitchell@ austin.org.au). 
Dr. Nasuti. Cytomorphology has always been at the core of the discipline since its inception. For many years before the advent of ancillary studies such as image analysis, immunocytochemistry, cytogenetics and molecular techniques, it was the only procedure in use. Despite cytomorphology's stand-alone status as the only source of cellular information, in those early days it managed to produce impressive diagnostic accuracy in urine, FNA and body cavity fluid specimens. Due to the minimally invasive nature, rapid turnaround time (in some cases at the bedside) and relatively low production costs, cytomorphology is and has always been the biggest diagnostic bang for the buck. Currently another essential role for cytomorphology is as gatekeeper for the more expensive ancillary studies. Information obtained from these adjuvant tests is required to arrive at a precise diagnosis in the relatively small percentage of challenging cases not solvable by morphologic criteria alone. In the foreseeable future, I do not believe that a cheap, dependable technology will emerge that will take cytotechnologists and cytopathologists out of the diagnostic loop.

$\mathrm{Dr} . \mathrm{Ng}$. Many ancillary investigations (such as immunocytochemistry and polymerase chain reaction [PCR]based technology) require proper tissue identification. Morphologic correlation still plays a major role in both tissue selection and result interpretation. FNA and fluid cytology have the advantage of minimal invasion and are important preoperative investigative tools, complementary to tissue biopsy.

Dr. Schalper. The full use of the cellular pathology first proposed by Rudolf Virchow in the mid-19th century, ${ }^{2}$ one of the bases of occidental medicine that considers the cell as the fundamental unit of life and illness, places cytopathology in an outstanding place in current medicine. The role of cells in living organisms allow their morphologic study to reveal pathologic changes originating in diverse levels of complexity, from slight molecular disorders to those affecting the whole organism. Pathologic stimuli are many and different in nature, but morphologically detectable cell responses seem to be convergent, limited and therefore classifiable. The current knowledge in cellular pathology allows us to foresee that morphology will still be needed in cytodiagnosis, at least in obtaining the initial diagnosis. If necessary, algorithms, including complementary techniques, will be applied afterward to confirm the results in doubtful cases or to reach the precision required to choose an accurate therapy. Progress in conventional cytologic techniques, such as new fixatives and stains, use of efficient automatic machines to process samples and development of image analysis tools such as computational morphometry, will contribute to improve morphologic cytodiagnosis and standardization of cytologic technique. Telecytology will allow real-time discussion of cases and remote matching of images against huge databases. The extension in the availability of this tool will undoubtedly improve the uniformity of criteria and continuous education of students, cytopathologists and medical technologists, strengthening the role of the morphology in cytodiagnosis.

Taking into account the high diagnostic accuracy, speed, simplicity and cost-effectiveness of morphology and the high cost of most complementary techniques (making them prohibitive for many health centers) ${ }^{3}$ I have no doubt that morphology will continue to be essential in cytodiagnosis in the next decade.

Dr. Schmitt. Although ancillary techniques have become part of the diagnostic armamentarium in the pathology laboratory, morphologic analysis coupled with detailed clinicopathologic information will still play a pivotal role for diagnosis. Moreover, morphology is (and will be for the next 10 years) essential in selecting target cells for molecular approach. The erroneous interpretation of telomerase activity in lymphocytes on effusions is a good example of lessons to be learned.

Dr. Verhest. Morphologic features of the cell are the basement of the building of a reliable diagnosis in cytology. Every ancillary technique, from old-fashioned special stains to modern immunostaining or in situ hy-

Dr. Mulvany is Senior Specialist Pathologist, Anatomical Pathology Department, Austin Hospital, and Honorary Specialist Pathologist, Mercy Hospital for Women, Heidelberg, Victoria, Australia (nicholas.mulvany@austin.org.au).

Dr. Nasuti is Surgical Pathologist/Cytopathologist, Dianon Systems, Stratford, Connecticut, U.S.A. (nasuti@optonline.net).

Dr. Ng is Consultant Pathologist, Hong Kong Adventist Hospital, Hong Kong Sanatorium and Hospital, St. Teresa's Hospital and Tsuen Wan Adventist Hospital, Hong Kong SAR, China (ngwk@yahoo.com).

Dr. Osamura is Vice Chair, the Japanese Society, and Professor of Pathology, Tokai Univeristy School of Medicine, Boseidai Isehara-city, Kanagaw, Japan (osamura@is.icc.u-tokai.ac.jp).

Dr. Schalper is Professor of Pathology, Faculty of Medicine, San Sebastian University, and Chief, Division of Pathology and Cytopathology, Las Higueras Hospital, Concepción, Chile (jschalper@gmail.com). 
bridization, rests on the morphologic recognition of the counterstained target cell. The first goal is to improve sensitivity and specificity of conventional cytology.

In most instances in facilities with low resources, cytology will remain the only efficient tool for triaging patients and providing an accurate diagnosis for patient management.

Dr. Vielb. It is anticipated that new technologies will not replace morphologic techniques, but rather will serve as ancillary tools for extracting complementary data to morphology. This may be very useful for better stratifying the treatment of patients according to special tumor subtypes defined by gene expression profiling (breast cancer is a well-known example). On the other hand, cytopathologists may also learn a lot from these molecular-based classifications and try to define new morphologic features closely associated with discrete prognostic biomarkers or predictive factors of success of a given therapy.

\section{The Role of Imaging Techniques}

FNA under computed tomographic, sonograpbic or fluoroscopic guidance for cytologic diagnosis bas become an indispensable component of the workup of many lesions.

\section{A. In your clinical setting, who is performing guided FNA?}

Dr. Akerman. In our facility, radiologists perform the FNAs, often together with a cytotechnologist.

Dr. Alves. At São Paulo University School of Medicine, Brazil, whenever possible the cytopathologist performs guided FNA, ensuring quality of the sample and insertion of cytomorphology in the clinical imaging context. However, in most Brazilian services, this is performed by radiologists. In my opinion, this is because of an insufficient number of cytopathologists and inadequate payment, situations that should be addressed by our professional societies.

Dr. Bubendorf. Traditionally, FNAs are performed by the clinicians in our institution. This is done in tight contact with us. We provide immediate feedback on the quality of the specimens and organize regular workshops on FNA technique. This is supplemented by monthly conferences in which cytologic findings are discussed at the microscope with the clinicians (e.g., pulmonologists and endocrinologists). In addition, we provide rapid on-site cytology in selected fields such as endoscopic FNA of the pancreaticobiliary tract or transbronchial FNA.

Dr. Colgan. Pathologists perform very few FNAs in Toronto clinics and hospitals. Superficial FNAs of thyroid and salivary gland are performed by the surgeons. Deep FNAs are performed by the imaging specialist (radiologist) under image guidance. Many pathologist authors have stated their great preference for the performance of FNAs by pathologists, citing better specimen adequacy and easier availability of historical and clinical data. In large institutional laboratories, such as the Mount Sinai Hospital (Toronto), these perceived benefits do not outweigh the inefficiencies of having pathologists absent from their laboratory duties in order to respond to requests for FNAs when trained, dedicated oncologic surgeons and radiologists are already at the patient's bedside, poised with needle in hand!

Dr. Kapila. In our clinical setting, guided FNAs are a combined effort of the radiologist and the cytopathologist. Localization of the needle tip in the mass is performed by the radiologist. The actual aspiration is done by the cytopathologist, who also immediately checks the adequacy of the specimen.

Dr. Katz. At MD Anderson we have four aspiration clinics; however, only one is for pathologistperformed FNAs. The others service deep FNAs, with cytopathology fellows and staff pathologists providing immediate assessment and feedback to radiologists who perform CT-guided, ultrasound-guided and fluoroscopy-guided FNAs or they perform services for other clinicians (e.g., pulmonologists, gastroenterologists) who perform endoscopy-guided FNAs. The flow of communication between cytopathologists and radiologists or other clinicians during the FNA procedure ensures sufficient tissue is procured for cytology and ancillary testing. In lymphoma diagnosis, we employ Coulter Counters to perform cell counts and the FNA continues with additional passes (usually 2-3 are sufficient) until at least 10 million cells are

Dr. Schmitt is Professor of Pathology and Senior Research, Medical Faculty of Porto University and IPATIMUP, Porto, Portugal (fschmitt@ipatimup.pt).

Mr. Serizawa is Cytotechnologist, Tokai University School of Medicine, Boseidai Isehara-city, Kanagaw, Japan (serizawa@is.icc.u-tokai.ac.jp). Dr. Verhest is Head, Department of Pathology, Cytology and Cytogenetics, Institut Jules Bordet, Cancer Center of the Free University of Brussels (ULB), Brussels, Belgium (alain.verhest@bordet.be).

Dr. Vielh is Head of Cytopathology, Department of Pathology, Institut de Cancérologie Gustave Roussy, Villejuif, France (vielh@igr.fr). 
obtained for immunophenotyping by flow cytometry or cytospin immunocytochemistry, proliferation and interphase FISH studies on cytospins.

Dr. Mulvany and Ms. Mitchell. In our clinical setting, all guided FNAs are performed by a radiologist. Crush artefact and low cellularity were common. Accordingly, a cytology scientist or cytopathologist now attends to ensure cell adequacy and optimum preservation of the aspirated material.

Dr. Nasuti. An on-site cytopathologist performs the critical role of determining cellular adequacy to avoid nondiagnostic specimens. Performance of this duty greatly reduces the need to repeat costly, time-consuming image-guided FNA procedures. The presence of an experienced, on-site cytopathologist during an imageguided (computed tomography [CT], magnetic resonance imaging [MRI], sonographic, fluoroscopic, bronchoscopic, colonoscopic or endoscopic) FNA procedure is essential, because only he or she is able to appropriately correlate the clinical and cytomorphologic findings necessary to render an immediate and accurate interpretation. Also, an on-site cytopathologist is uniquely qualified to reliably make the crucial decisions in regard to specimen allotment, for example, designating a portion of the typically sparse FNA specimen for studies requiring fresh cellular material, as is the case with flow cytometry and microbiologic cultures. Such a choice must be made at the bedside during the procedure and without hesitation. Failure to properly triage a specimen derived from an imageguided procedure is not without consequence. An inadequate amount of conventionally processed material will compromise the ability of the laboratory to perform the special staining procedures and immunocytochemistry often needed for further diagnostic characterization in difficult cases.

$D r . N g$. Image-guided FNA, either with ultrasound or computed tomography, is performed by trained radiologists, and free-hand FNA is performed either by clinicians or anatomic pathologists.

Dr. Schalper. In our experience, FNAs are mostly performed by a radiologist and occasionally by another specialist who is familiar with the organ or system in which the procedure is being performed. For the past 25 years, we have preferentially used ultrasound to guide FNAs in solid tumors of the thyroid gland, parotid glands, liver, pancreas and retroperitoneum and radioscopy in tumors located in the chest (specially in the lungs) with high diagnostic efficacy ( $>98 \%$ ). In $\sim 80 \%$ of those cases, we obtained sufficient material to make a cell block.
Dr. Scbmitt. In Portugal, cytopathologists, radiologists and clinicians or surgeons perform FNA. It is clear that cytopathologists perform better than the others; however, I agree that training of the other personnel is essential for the success of the technique. In aspirations of deep organs performed by radiologists or clinicians, the cytopathologist is in the room to assess the quality of the aspirated material, as well as to obtain correct material for ancillary techniques. ${ }^{4}$

Dr. Verbest. In our setting, a cancer center to which patients are referred, guided FNA is performed by radiologists, internists or surgeons. Fifteen years ago, I set up an FNA clinic in the general hospital, with the cytopathologist assisting the radiologist by assessing the cellularity of the aspirate and proposing a first "blitz" diagnosis when possible.

Dr. Vielh. At the Institut de Cancérologie Gustave Roussy (Villejuif, France) guided FNA is usually performed by a cytopathologist with the aid of a radiologist. The sampling is made by the pathologist, with on-site evaluation based on a rapid stain and usually a definitive diagnosis and a pathology report delivered directly to the clinician through our institutional information system.

\section{B. How often are core biopsies obtained when FNA is performed?}

Dr. Akerman. In the case of musculoskeletal tumors, core biopsies are obtained in most cases. In the case of breast lesions and enlarged lymph nodes, they are obtained increasingly more often.

Dr. Alves. Regarding the need for core biopsy, whenever major diagnostic criteria rely on the finding of capsular or vascular invasion, as well as on tissue architecture pattern, it is of major relevance.

Dr. Bubendorf. There is no general policy as to whether or not FNA should be accompanied by core biopsy. This depends on the organ type and the preference of the clinician. However, in the case of a positive cytologic diagnosis, histologic confirmation is usually thought to be unnecessary. Exceptions include a first diagnosis of lymphoma, in which histology is often required for determining the histologic subtype and also demanded in case of clinical trials. In patients with clinical suspicion of breast cancer, core biopsy has almost totally replaced FNA.

Dr. Colgan. Core biopsies have displaced cytologic FNAs as the specimen of choice in suspected malignant prostate, breast and soft tissue lesions in the Mount Sinai Hospital (Toronto) laboratory. Cytolog- 
ic FNAs of breast lesions are still used in some clinic situations to assist in the initial assessment of clinically benign breast masses or in the diagnosis of suspected recurrent, multifocal or multicentric or metastatic disease. For example, a positive FNA specimen of suspected nodal metastatic breast carcinoma will avoid any unnecessary sentinel lymph node biopsy because patients can move directly to axillary node dissection. Cytologic FNAs of deep thoracic and abdominal sites are still very common, but, increasingly, skinny core biopsies are also being received from thoracic and abdominal deep sites as well. For example, a core biopsy of an omental cake in a woman with suspected unresectable disseminated ovarian cancer can yield a definitive histopathologic diagnosis, thus permitting the initiation of neoadjuvant chemotherapy as first-line treatment without the need for a laparotomy.

Dr. Kapila. Very occasionally a core biopsy is taken at the time of doing a FNA.

Dr. Katz. The use of core biopsy is definitely increasing at our institution. We have always been advocates of good core biopsies when obtaining this tissue can enhance and refine the diagnosis. This is especially so for soft tissue and bone lesions.

Dr. Mulvany and Ms. Mitchell. Occasionally, fine needle aspirates are obtained concurrently with the core biopsies. Biopsies are done at the discretion of the radiologist. The situations for performing them include small lesions, the likelihood of low cellularity (e.g., fibrotic lesions) or a wish to avoid patient recall.

$\mathrm{Dr} . \mathrm{Ng}$. For deep-seated lesions (e.g., lung or liver lesions), core biopsies are sometimes taken simultaneously with FNA. In fact, core biopsy (together with frozen section monitoring) is preferred over FNA for investigation of deep-seated lesions in some hospitals. Core biopsy allows more thorough assessment of architectural patterns and yields more intact tissue fragments for immunohistochemistry. For some superficial lesions (e.g., breast lesions), FNA is still the first line of pathologic investigation. Core biopsies are taken only when indicated and often after FNA (e.g., for distinguishing in situ from invasive malignancy). For certain superficial lesions, especially those occurring in head and neck region (e.g., thyroid or salivary gland lesions in which the lesions are potentially vascularized or tumor implantation is a concern), only FNA is performed.

Dr. Scbalper. In $\sim 10 \%$ of FNA specimens from different locations we made a core biopsy, which was necessary to determine the infiltrative character of the tumor (staging) in order to follow the appropriate therapeutic protocol.

Dr. Scbmitt. Rarely. In general, when core biopsy is needed, it is performed at a different time.

Dr. Verhest. Very rarely, core biopsy and FNA are performed concomitantly. Without clinical contraindications, core biopsy is usually preferred by the oncologist asking for a histologic grade, typing of the tumor and predictive markers by immunostains or fluorescence in situ hybridization (FISH). A paraffin block is stored for possible further investigation.

Dr. Vielh. In nodular lesions of the breast an $80 \%$ reduction in the number of preoperative core biopsies and frozen sections has been observed in the past 2 years since we set up a 1-day clinic based on FNA.

\section{C. Is core biopsy necessary?}

Dr. Akerman. In my opinion, the diagnostic accuracy is increased when FNA and core biopsy are performed in the same sequence by the cytopathologist. ${ }^{5}$ This double sampling makes the most of the advantages of FNA and core biopsy. Out-patient procedures, rapid primary diagnosis and excellent cytomorphology (FNA) combined with assessment of tissue architecture (core biopsy) most often provide sufficient material for various ancillary methods.

This double sampling is not necessary in every case. With a simple flow chart it is possible to select cases in which FNA and core biopsy may give a more accurate diagnosis than only FNA.

With FNA the first sample is immediately stained (Diff-Quik or rapid hematoxylin-eosin [H-E]). These smears are ready for evaluation in 3-4 (Diff-Quik) or $6(\mathrm{H}-\mathrm{E})$ minutes. The patient remains in the aspiration room. After immediate evaluation of the rapidly stained smears, the cytopathologist decides whether the samples are sufficient or further FNAs or FNA and core biopsy are required.

Dr. Colgan. Although some cytopathologists may be reluctant to accept the superiority of core biopsies over traditional cytologic FNAs, core biopsy specimens do have significant advantages in many disease sites for three reasons. First, only core biopsies permit assessment of the architecture (histopathology) of the tissue or tumor, which is often essential in reaching a precise diagnosis. For example, unlike breast cytologic FNAs, breast core biopsies can reliably distinguish between ductal carcinoma in situ and invasive ductal carcinoma. Second, image-guided core biopsies are often superior to manual cytologic FNA techniques in retrieving a representative sample. Directed breast 
needle coring of mammographic abnormalities is an example of this superiority. Third, cores can identify prognostic parameters that cannot be assessed within cytologic FNAs. For example, the presence of lymphovascular space involvement by invasive ductal carcinoma within a breast needle core biopsy may lead to drastically different initial treatment.

Needle cores will not render cytologic FNAs obsolete. In those sites or diseases in which cytology remains paramount in diagnosis, such as in thyroid FNA, cytologic specimens will remain needed and valued.

Dr. Kapila. In my opinion a core biopsy is not necessary provided a check for adequacy of material obtained is done at the time of the procedure. A core biopsy is helpful and may be attempted if repeated attempts at FNA fail to obtain adequate material.

Dr Katz. Other areas in which core biopsies should be obtained include retroperitoneal or mediastinal lymphomas where tissue yield may be scanty, pulmonary biopsies, breast biopsies for difficult to interpret proliferative or papillary lesions or to diagnose invasion in an initial diagnosis of breast cancer, for any FNAs in which cellular yield is poor or where an extensive diagnostic workup encompassing immunocytochemistry stains is anticipated and where the cell block obtained from the FNA may be inadequate. At our institution we perform a touch imprint off the core biopsy for immediate assessment of adequacy. One area that has not yet been extensively utilized for core biopsy is thyroid aspiration, because sufficient tissue usually can be obtained for a satisfactory cytologic diagnosis.

Dr. Mulvany and Ms. Mitchell. In the aforementioned clinical settings, core biopsy is more likely to provide a greater amount of material and a more definitive diagnosis than FNA. At other sites, such as thyroid, lung, mediastinum or retroperitoneum, FNA is the technique of choice.

OSE $[$ NDR IC $-($ NDRos ICOS + OSF $)]=$ TCS

Figure 2 IC $=$ institutional direct cost per case based on the technical and professional fees and the weighted averages of the costs of ancillary laboratory studies and guidance procedures, ICos $=$ institutional cost per case with on-site evaluation, NDR= average reported nondiagnostic rate without on-site evaluation, NDRos = nondiagnostic rate with on-site evaluation, OSE = number of annual on-site events, OSF = on-site professional fee per case, $\mathrm{TCS}=$ total cost savings.
Dr. Nasuti. The direct institutional cost savings achieved by minimizing nondiagnostic specimens and hence avoiding repeat image-guided FNA procedures may be substantial. The amount of money saved by a facility using an on-site cytopathologist can be calculated based on a recently published formula (Figure 2). ${ }^{6}$ The direct cost savings to medical institutions by an effective on-site diagnostic service should by no means be the only consideration for its eventual deployment by a laboratory. One must also take into account indirect costs to patients by avoiding repeat FNA image-guided procedures. Included among these is increased risk of morbidity inherent in repeat procedures, the need to take additional time off work and prolonged hospital stays.

Dr. Ng. Sometimes yes. Core biopsy has the advantage of allowing more thorough assessment of architectural patterns. Thus, whenever assessment of architectural patterns is the key issue (e.g., in distinction between in situ or invasive malignancy of breast), core biopsy is indispensable as a preoperative tool. Immunohistochemistry can readily be applied in core biopsies. This is in contrast to cytology smears, in which nonspecific background staining is sometimes a major problem in immunocytochemical study. On the other hand, core biopsy is associated with a higher sampling error rate.

Dr. Schmitt. Daily practice and scientific evidence have demonstrated that FNA can give information similar to that provided by core biopsy, while saving money and time. ${ }^{4}$ In breast cytology, the techniques are complementary and have a role in the investigation of different lesions. For example, we prefer core biopsy in the study of microcalcifications.

Dr. Verbest. The question could be whether FNA is still necessary. Most clinicians in our facility prefer core biopsy for breast, prostate and liver pathology. However, we cytopathologists know that in some cases cytology is more informative than a necrotic or sclerotic biopsy.

Dr. Vielh. On-site examination and immediate diagnosis of FNA preoperatively makes it possible to indicate core biopsies when needed, for example, if the cytology raises suspicion or is unsatisfactory. However, core biopsies are mandatory when a neoadjuvant chemotherapy is planned and, of course, when mammography shows microcalcifications.

\section{D. With future technical advances in imaging, will} the value of cytology decrease?

Dr. Alves. Technical advances are great opportuni- 
ties for cytopathologists. We strongly advise residents in radiology programs to spend 3 months in a pathology program and the reciprocal training of pathology residents in an imaging methods program. The real challenge seems to be how the Societies of Radiology and Cytopathology will define common rules for the role of each specialist in these important areas.

Dr. Bubendorf. Future technical advances in imaging will not decrease the value of cytology. Even the most advanced imaging technique will not reach $100 \%$ sensitivity but may suffer from unsatisfactory specificity. Thus, morphology including cytopathology will remain the golden standard.

Dr. Colgan. Future technical advances in imaging will likely see increasing use of needle core biopsies. Cytology will still remain valuable, but its use as a "stand-alone" technique for patient management will likely diminish. Cytologic assessment of FNA and core biopsies will be combined with other immunocytologic and genetic data to reach a final comprehensive diagnosis and assessment.

Dr. Kapila. I doubt if the value of cytology is going to decrease with future technical advances in imaging. In fact, it will gain more importance because suspected diagnosis on imaging techniques will have a tissue confirmation on FNA without resorting to core or open biopsies.

Dr. Katz. FNA cytology is a growth industry fostered by an explosion in sophisticated endoscopic equipment, new needles and transducers and new portable ultrasound machines that can be taken to the bedside. With the advent of new adjunctive techniques such as positron emission tomography (PET) scanning, more lesions will be biopsied. With ultrasound more thyroid lesions are being discovered and more FNAs are being performed. Endoscopic-guided aspiration of lesions of the gastrointestinal and respiratory tract are growing exponentially. FNAs of lymphomas are increasingly performed.

Dr. Mulvany and Ms. Mitcbell. The use of FNA may well decrease as technical advances in imaging are introduced. Already we have witnessed a decrease in FNA of the prostate and in stereotactic breast examinations. ${ }^{7}$

$\mathrm{Dr}$. Ng. Perhaps yes, especially for deep-seated lesions. Radiologists have the tendency to obtain core biopsies using a biopsy needle of smaller gauge size.

Dr. Scbalper. The progress in imaging techniques regarding resolution and sophistication of equipment such as ultrasound transducers, has expanded the use and safety of FNA (e.g., we can now puncture thyroid gland nodules $<5 \mathrm{~mm}$ ). New image analysis methods, such as confocal laser scanning microscopy (CLSM) and multiphoton laser scanning microscopy (MPLSM), will lead first to a virtual road of the needle during the FNA and then to a virtual and intelligent needle (laser-induced fluorescent spectrophotometry systems). Therefore I am fairly sure that advances in imaging techniques will not decrease, but will boost the value of cytology as a diagnostic tool..$^{8}$

Dr. Schmitt. The value of cytology will increase because more small lesions will be detected and studied by aspiration and cytology can be complementary to dynamic and metabolic imaging techniques, such as positron emission tomography.

Dr. Verhest. To me this is utopia. It was said many years ago that imaging would better assess liver steatosis and cirrhosis than biopsy. Immunoassays, molecular diagnoses and image analysis of lesions' extension are attractive tools that remain blind without morphology. They will not threaten the role of cytology, but can in certain applications enhance its value.

Dr. Vielh. Here again, technical advances based, for example, on contrast imaging agents for exploring vascularization and elastography may complement morphology testing in the near future but will probably not replace it.

\section{The Role of Immunocytochemistry}

Immunocytochemistry bas become an important adjunct method for cytologic diagnosis. The techniques that are applied to surgical pathology are also applicable to cytology. However, cytology fixatives may cause variations in the results.

\section{A. What preparations and fixatives do you recommend for cytologic specimens?}

Dr. Alves. Ethanol-based fixatives are useful for most antigens. Paraformaldehyde-periodate-lysine solution may also be useful to preserve both cytomorphology and immunoreactivity. The advent of non-avidin/ biotin amplification systems also add a better signalto-noise ratio in previously stained (Papanicolaou or $\mathrm{H}-\mathrm{E})$ slides, thus targeting the reaction on the most relevant cells. The fixatives for liquid-based cytology are also useful adjuncts, as are cell blocks.

Particularly in cases with neoplasms in advanced stages, immunocytochemistry will possibly grow as an adjunct technique, confirming a tumor as a metastasis or a second primary, selecting a few sites to be exam- 
ined in the search of a primary unknown metastasis. I strongly feel that immunodetection of molecular markers on cytopathologic samples (either prestained smears or the stock of liquid-fixed samples) will play a major role as a guide for molecular-targeted therapy, because some evidence points to a non-neglectable discordance of immunoexpression of receptors such as epidermal growth factor receptor (EGFR) in primary tumors vs. metastases.

Dr. Akerman. Direct smears, cytospin preparations, cell block preparations and liquid-based cytology (ThinPrep) have been investigated. In my facility, immunostaining on cell block preparations is the method of choice. ThinPrep seem promising but needs further evaluation. In the diagnosis of enlarged lymph nodes, flow cytometric immunophenotyping is applied more often than immunocytochemistry.

Dr. Bubendorf. Immunocytochemistry (ICC) works well on specimens that were fixed with ethanol-based fixatives (e.g., Delaunay or SprayFix). Liquid-based preparations can also be used but are not a requirement. Due to the different fixations in cytology, one cannot apply the same protocol as in histology, and the optimal protocol needs to be defined for each antibody. Some prefer to use cytoblocks for immunocytochemistry. In fact, cytoblocks have certain advantages. Cytoblock sections can be run with the same protocols and in the same laboratory as histologic sections, a higher number of analyses may be possible, and they can be reanalyzed even after long archival periods. We prepare cytoblocks from the remaining sediment of selected cases in which a high number of immunocytochemical analyses is foreseeable based on cytomorphology. However, one should keep in mind that in many instances there is not sufficient material available for a cytoblock. By restricting immunocytochemistry to cytoblocks, one gives away the opportunity to analyze those other specimens in which only a smear or a cytospin is available.

Dr. Kapila. In our laboratory, $95 \%$ ethanol-fixed slides give good results. Sometimes we resort to cell blocks if cellular material is very scant.

Dr. Katz. Most of our specimens are air dried and then fixed in acetone just before immunostaining. A few antibodies require that methods for antigen retrieval be performed or require fixation in formalin. Many FNAs are cell blocked and then treated similar to histologic preparations.

Dr. Mulvany and Ms. Mitchell. In our department, all fluids are received fresh and centrifuged. The di- rect smears are either alcohol fixed or air dried and stained with Papanicolaou or modified Romanowsky stain, respectively. Agar clot sections are also prepared from the centrifuged cell sediment. The clots are fixed in formalin, processed in paraffin and histologically examined.

If FNA is performed on a solid mass, the aspirated material is promptly smeared and the slides stained as previously described. The syringe and needle are rinsed in Hank's solution and the wash prepared for cytospin or clot sections.

Dr. Nasuti. Immunocytochemistry utilized in conjunction with cytomorphologic criteria offers the chance that a cytologic specimen acquired via minimally invasive means becomes the sole diagnostic procedure leading to appropriate patient therapy. When such a goal is achieved the expense and increased potential morbidity of an intervening surgical biopsy can be avoided. The probability that cytomorphology in combination with immunocytochemistry will become definitive diagnostically is wholly dependent on the specimen processing techniques employed by the cytology laboratory. One must be able to preserve cellular material in a hardy state, because its survival may be questionable after being subjected to commonly used immunocytochemical protocols that can contain destructive antigen retrieval steps.

Cell blocks are the all-purpose approach used to preserve cellular material for both special stains and immunocytochemistry. It can be used for every conceivable type of cytologic specimen provided that adequate cellularity is present in the appropriate fluid medium. In theory and often in practice, a paraffinembedded cell bock will withstand the same immunohistochemical procedures as a similarly processed wax-embedded tissue block of a surgical specimen. The problem of course is having a sufficient amount of cellular material to justify the additional cost, labor and time required to attempt ancillary procedures. This is true particularly of cases in which a panel of immunocytochemical stains is desired to determine the tumor of origin in malignant pleural effusions.

If for any reason the cellularity necessary to make a cell block is not an option in certain situations, all is not lost. Immunocytochemical procedures have been developed and documented that can be applied to direct smears, monolayers and even Millipore filters.9,10 Unfortunately, in such scenarios the menu of immunostains is generally limited to antibodies that do not required harsh antigen retrieval steps. Otherwise, obliteration of the much more delicate cellular material present on standard processed cytology slides would result. In the near future, it is unlikely that great improvements in the cellularity of specimens will 
occur. Nor is it likely that commonly used cytologic preparatory procedures will be adjusted to enhance the capability of cellular material to survive antigen retrieval. Therefore hope for the future of immunocytochemistry lies in the slowly but steadily growing list of commercially available antibodies with a kinder and gentler effect on the precarious nature of cells wet fixed to glass.

$\mathrm{Dr}: \mathrm{Ng}$. In my laboratories, immunocytochemistry is usually performed on paraffin-embedded cell block sections. FNA or effusion cytology specimens are initially submitted in $50 \%$ ethanol. The fluid is then centrifuged for subsequent cytospin or cell block preparations. The cytospin slides are postfixed in $95 \%$ ethanol for several hours before further staining. For cell block preparations, the sediments are postfixed in $10 \%$ neutral buffered formalin for 1 hour, centrifuged again, mixed with agar and processed as routine paraffin blocks. Immunocytochemistry performed on cytospin preparations sometimes produces satisfactory results, especially for nuclear antigens (such as thyroid transcription factor-1). For cell block sections, the protocol for immunocytochemical study is similar to that for surgical biopsies. Antigen retrieval is usually carried performed with a pressure cooker.

Dr. Osamura and Mr. Itob. We have been using ethanol-fixed materials with satisfactory results. We can keep the slides in ethanol (wet state) for several months easily. We use the indirect immunoperoxidase method. It would be preferable to use peroxidase-labeled IgG Fab'2 to facilitate its penetration in the cells. Cell transfer technique is very useful when the detection of multiple antigens is required when the

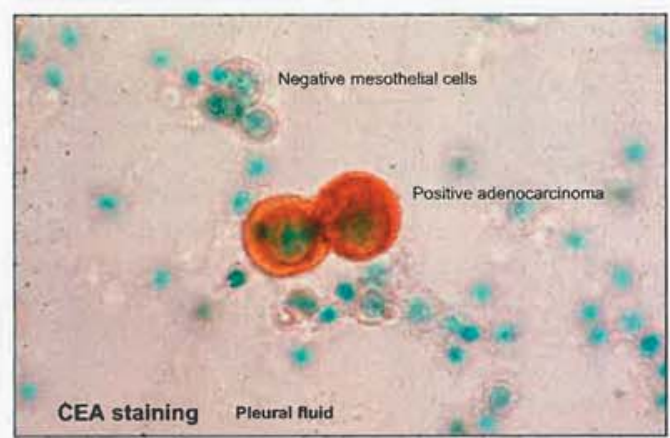

Figure 3 immunocytochemical positive staining for carcinoembryonic antigen (CEA) on the metastatic pulmonary adenocarcinoma in pleural fluid. Note that mesothelial cells are negative for CEA. number of slides available is limited. For the detection of multiple antigens, fluorescence techniques such as nanocrystal quantum dots (Qdots) are more frequently used.

Case-Based Illustration. Differential diagnosis in clinical cytology is probably best described in the detection of malignant cells by carcinoembryonic antigen (CEA) in the body fluid (Figure 3). ${ }^{11}$ Although CEAnegative carcinoma cells are known, CEA-positive benign cells are exceptional. We have been successfully detecting adenocarcinoma of the lung in the pleural fluid and colorectal adenocarcinoma in the peritoneal fluid.

Differential diagnosis between carcinoma and malignant lymphoma is best illustrated in the case of large cell anaplastic lymphoma, in which CD30 and CD 45 are positive whereas epithelial markers, including EMA and CEA, are negative.

Detection of primary site of metastatic malignant tumors can be best illustrated by metastatic adenocarcinoma of the lung. The tumor cells are not only positive for CEA, keratin and other neuroendocrine markers, but they are also positive for thyroid transcription factor (TTF) $-1 .{ }^{12} \mathrm{CDX} 2$ is an enterocolonic marker that works for differential diagnosis for the metastatic tumor of enterocolonic primary tumors.

Dr. Schmitt. We recommend alcohol-fixed smears or formalin-fixed, paraffin-embedded cell blocks.

Dr. Schalper. To apply immunocytochemistry in cytopathology, we first recommend drying cytologic samples and then cytocentrifuging in room air, followed by chemical fixatives (ethanol, acetone or phor$\mathrm{mol}$ ) for a brief period (10-20 $\mathrm{min}$ ), to achieve the best relationship between structural and antigenic preservation. We recommend a 5 -minute fixation with $95 \%$ ethanol for epithelial malignancies and sarcomas and 15 minutes in acetone for lymphomas and melanomas.

Dr. Verbest. The difficulty in selecting appropriate fixatives for intracellular antigen detection on cytology samples has discouraged us from applying this technique, limiting immunostaining in cell blocks.

Dr. Vielb. Type of cytologic preparation and choice of fixative are of tremendous importance, and there are still too few recommendations and guidelines about the critical requirements for their optimal use. Unfixed, air-dried cytologic preparations are stored at $4^{\circ} \mathrm{C}$ for $<1$ week, until they are fixed in acetone for 10 minutes or in a 1:1 mixture of methanol and absolute methanol before immunostaining for hematopoietic or nonhematopoietic markers, respectively. We also 
use cell blocks, following the usual histologic process of fixation and immunostaining.

\section{B. Name a few challenging kinds of cases that can benefit from this technique.}

Dr. Akerman. Diagnosis of malignant melanoma can benefit from immunocytochemistry techniques, as can differential diagnosis between Ewing's sarcoma/primitive neuroectodermal tumor (PNET) and poorly differentiated Ewing's sarcoma-like synovial sarcoma, diagnosis of anaplastic large cell lymphoma and diagnosis of an unknown primary when a metastatic lesion is the first sign of disease (Figure 4).

Dr. Bubendorf. Immunocytochemistry has become an indispensable diagnostic tool in our laboratory, with applications that are often the same as those in histology. Commonly used and important examples are TTF-1, CK7 and CK20 (adenocarcinoma of the lung vs. metastasis of extrapulmonary adenocarcinoma), CDX2 (colorectal adenocarcinoma), BerEP-4 and calretinin (rare carcinoma cells in pleural effusions), T4/8 ratio in bronchoalveolar lavages (sarcoidosis) and immunofluorescence for detection of infectious agents (Pneumocystis, cytomegalovirus and others).

Dr. Kapila. The cases that benefit from immunocytochemistry and in which we have found this to be useful in daily practice are categorization of round cell tumors; differentiating anaplastic carcinoma from non-Hodgkin's lymphoma; typing of non-Hodgkin's and Hodgkin's lymphoma; and identification of neuroendocrine tumors, medullary carcinoma thyroid, nonclassic melanomas and gastrointestinal stromal tumors (GISTs).

Dr. Katz. ICC is indispensable to the diagnosis, clas-

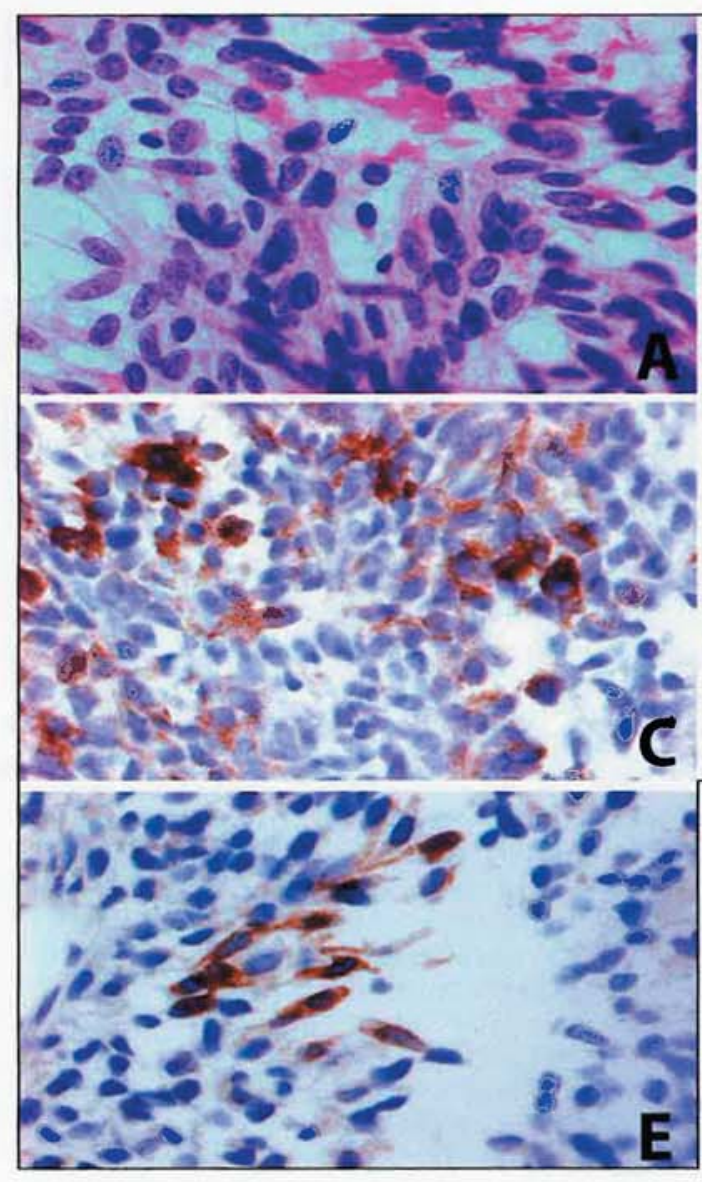

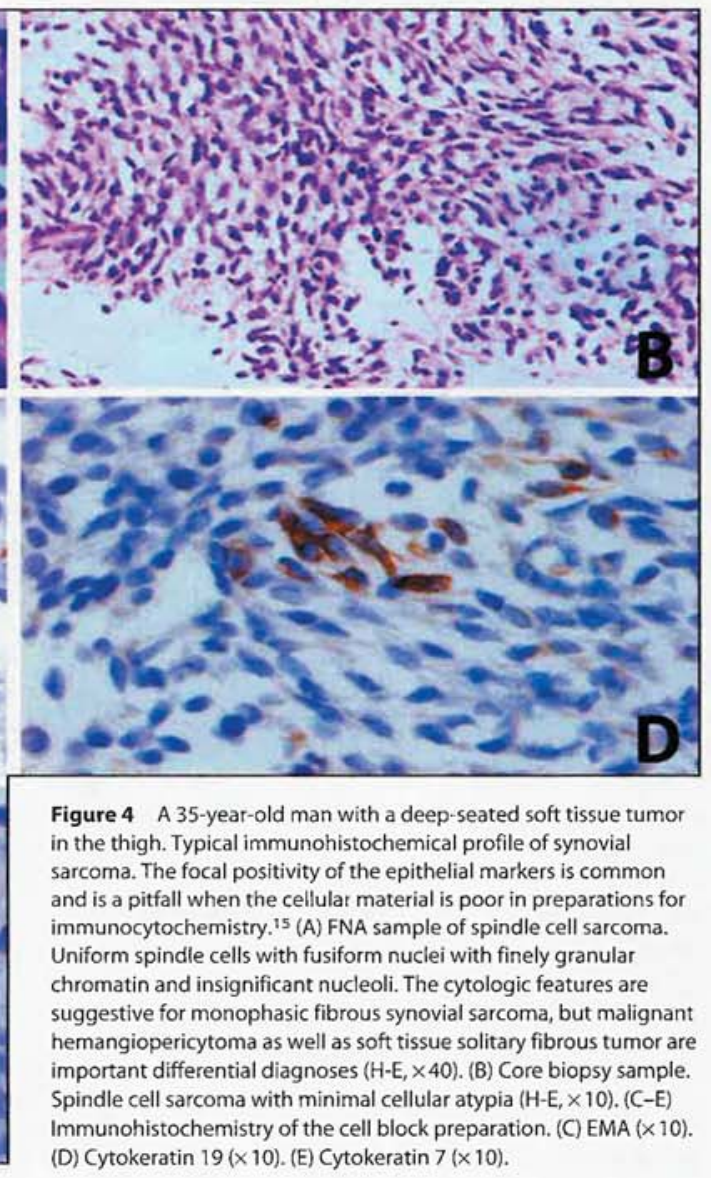

Expectations and Projections for Nongynecological Cytology
Acta Cytologica 2017;61:373-407

DOI: $10.1159 / 000477713$ 

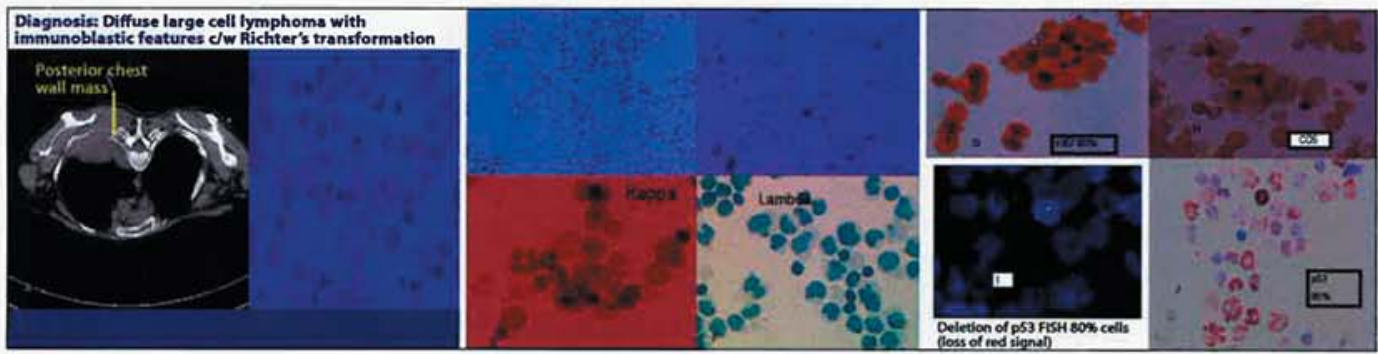

Figure 5 A 69-year-old woman with a history of CLL with early progression of disease while on chlorambucil. She presented several years later with a large posterior chest wail mass that was positive on PET scan. An FNA was performed under CT guidance (A). Large lymphoid cells with prominent nucleoli consistent with Richter's transformation ( $B$, Diff-Quik, $\times 400$; C, Papanicolaou stain, $\times 100 ; D$, Papanicolaou, $\times 400$ ).

(E) Monoclonal $k$ light chain expression on $100 \%$ of Ficoll purified cells (AEC, $\times 400)$. (F) Lambda light chain expression negative $(\times 400)$. (G) Ki-67 labeling index of $80 \%$ in lymphoid cells consistent with high-grade lymphoma $(\times 400)$. (H) CD5-positive cells consistent with origin from CLL/SLL $(\times 400)$. (I) Deletion of p53 by FISH in $80 \%$ of cells seen as loss of red compared to green signals (Vysis CLL probe set). (J) Positive nuclear stain for p53 by immunocytochemistry in $80 \%$ cells consistent with transformed CLL/SLL (AEC, $\times 400$ ).

sification and prognosis of many neoplasms. A few examples of its use at M.D. Anderson Cancer Center are:

1. A battery of lymphoid markers and $\mathrm{Ki}-67$ are performed on Ficoll-Hypaque purified lymphoid cells in both FNAs and effusions of lymphomatous origin for classification, diagnosis and grading of nonHodgkin's lymphoma using the WHO terminology. The diagnosis of Hodgkin's lymphoma is confirmed by ICC using CD $30, \mathrm{CD} 15, \mathrm{PAX} 5$ and CD20. In 2006 close to 600 FNAs were performed for lymphoma diagnosis with ancillary studies.

2. Use of CK7, CK20, TTF-1, CK5, CK6, p63, chromogranin, synaptophysin for accurate subtyping of lung cancers into small cell vs. non-small cell, squamous vs. adenocarcinoma and carcinoid.

3. Use of pan-cytokeratin, vimentin, CD10, CK7, Ulex Europaeus, and LeuM1, for classification of renal tumors.

4. Use of cytokeratins, TTF-1, calretinin, melanoma antigen, CD45, CD30, CK 117, OCT4, CA125, and CDX 2 for unknown primary tumors.

Figure 5 presents a 69 -year-old woman with a history of CLL with early progression of disease while on chlorambucil.

Dr. Mulvany and Ms. Mitchell. Immunocytochemistry (ICC) is of inestimable assistance in the diagnosis of, for example, malignant lymphoma, melanoma, Merkel cell carcinoma, mesothelioma, neuroendocrine carcinoma and soft tissue tumors. ${ }^{16}$

$\mathrm{Dr}$. Ng. The following cases could benefit from the technology.
Cytospin preparations:

1. TTF-1 staining for confirming lung primary in cases of metastatic adenocarcinoma in effusion cytology samples.

2. Tdt staining in diagnosing lymphoblastic lympho$\mathrm{ma}$ in FNA.

Cell block sections:

1. Nuclear stains, which can be applied with equally satisfactory results in paraffin-embedded cell block sections.

2. Smooth muscle actin or p63 staining for demonstrating myoepithelial cells in breast FNA for intraduct papilloma.

3. Cytokeratin staining for demonstrating epithelial tumor cells in mediastinal FNA for thymoma or lymph node FNA for metastatic nasopharyngeal carcinoma.

4. CD117 staining for confirming the diagnosis of gastrointestinal stromal tumor in intraabdominal FNA.

Dr. Osamura and Mr. Itob. IHC (applied on tissue sections) and ICC (applied) on cytologic smears) has been well accepted as an ancillary technique for diagnostic pathology and cytology. IHC and ICC are now efficiently used for the following cases: (1) differential diagnosis between benign and malignant tumors; (2) differential diagnosis of malignant tumors, such as, carcinomas vs. lymphomas vs. sarcomas; and (3) prognostication.

Dr. Schalper. Some interesting situations that would benefit from the use of immunocytochemistry in cytologic samples are: (1) definitive diagnosis of malignant 
small round cell tumors of childhood, (2) differential diagnosis between reactive mesothelial cells or mesothelioma and adenocarcinoma, (3) differentiating between major tumor categories, such as carcinoma vs. non-Hodgkin's lymphomas vs. sarcomas. ${ }^{13,14}$

Dr. Schmitt. ICC has become important not only for diagnosis but also to assess prognostic and predictive factors on cytologic material. Most of the situations in which we used ICC on histologic sections can be reproduced on cytology. Some examples are characterization of mesotheliomas (calretinin, MOC 31, Lewis antigens) and identification of carcinomas of unknown primary in effusions or lymph nodes aspirates (e.g., panel of cytokeratins, TTF-1, cdx-2, CA 125). Several markers have been advanced as adjunct for the differentiation between follicular adenoma and carcino$\mathrm{ma}$ on aspirates. One of most promising approaches is the combined evaluation of galectin- 3 and CD 44 variant 6 to provide better results in terms of sensitivity, since none of these markers alone is $100 \%$ positive in carcinomas. However, some markers have definitively found their roles in cytologic diagnosis of thyroid lesions. In a poorly differentiated malignant thyroid neoplasm, identification of thyroglobulin precludes the diagnosis of angiosarcoma and strongly favors the diagnosis of anaplastic carcinoma. Based on the same rationale, calcitonin, chromogranin, synaptophysin, carcinoembryonic antigen (CEA) and thyroglobulin can be used to differentiate medullary carcinoma from follicular carcinoma. In breast cancer, ER/PR analysis is a useful tool to predict the therapy response. FNA is a suitable alternative to obtain cells to determine ER/PR status in cases in which presurgical therapy is the initial option; in inoperable, recurrent or meta-

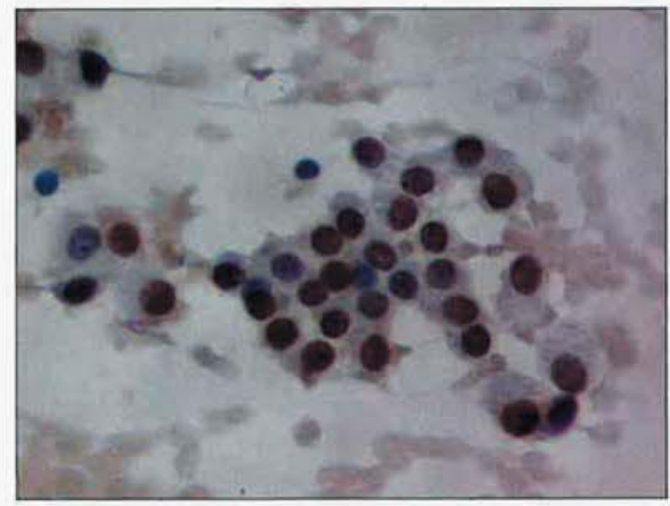

Figure 6 Alcohol-fixed smears from breast carcinoma showing cells with strong nuclear immunostaining for estrogen receptor. static tumors; and in advanced tumors in which serial hormone receptor studies may provide information regarding response to therapy. Our group and others have demonstrated the feasibility to estimate hormone receptor status in FNA from breast cancer (Figure 6) with excellent correlation with histologic assessment in the surgical specimens. Finally, sometimes we use ICC to characterize myoepithelial cells on breast FNAs (mainly p63) in attempt to differentiate benign and malignant lesions. ${ }^{17}$ Although ICC also can be used to help in the definition of lymphomas, in these situations we prefer to use flow cytometry.

Dr. Verbest. Differential diagnoses in malignant effusions or metastases of unknown origin are the most challenging cases in cytology. Immunostain algorithms help to sort these equivocal cases.

Dr. Vielh. As in surgical pathology, the most challenging cases are patients with undifferentiated tumors without a known primary, as well as the differential diagnosis of poorly differentiated neoplasms.

\section{C. Will immunocytochemistry continue to play an important role as an adjunct technique?}

Dr. Akerman. The combined diagnostic evaluation of routinely stained smears and immunophenotyping may (when the material is sufficient for a battery of antibodies) lead to a specific, correct diagnosis on which the definitive treatment can be based (primary surgery or neoadjuvant therapy followed by surgery or nonsurgical treatment). ${ }^{18}$

Dr. Bubendorf. The importance of immunocytochemistry will grow. High-throughput research tools such as DNA or oligo microarrays lead to new diagnostic markers and therapeutic targets that will need to be determined in histologic and cytologic specimens.

Dr. Kapila. Immunocytochemistry will continue to play an important role as an adjunct technique in the morphologic diagnosis of various lesions. However, with an increasing number of tumors having similar antigen expressions being discovered it is difficult to be categorical.

Dr. Katz. Immunocytochemistry will become increasingly important as an adjunctive technique, especially for targeted therapies. Already we see the role of rituximab for CD20-positive lymphomas, erbitux for EGFR-positive head and neck cancers and colon cancer, herceptin for Her2 neu, and Gleevec for CD117positive GISTs, and there will be many more markers to be discovered. 
Dr. Mulvany and Ms. Mitchell. ICC identifies surrogate markers for histologic cell type, and therefore the results often depend on the degree of tumor differentiation. Many other factors, both in vitro and in vivo, influence cell immunoreactivity. No single antibody possesses both high sensitivity and high specificity, and thus a panel of antibodies must be selected. Technical problems often arise due to lack of standardization in cell fixation, antigen retrieval, the particular antibody clone, sensitivity of the detection system and microscopic interpretation (intensity, percentage and staining pattern of lesional cells). ${ }^{19,20}$ Air drying or necrotic tumor cells can account for loss of antigen and negative results. In any single neoplasm the biomarkers may show significant changes with time, between the primary and metastatic tumor and following chemotherapy or radiotherapy. It is expected that over the next few years the use of ICC will increase as it becomes more refined in application and the positive and negative predictive values are better understood.

Dr. Scbalper. Immunocytochemistry will remain important as a complementary diagnostic method in the coming years and possibly as the best way to identify malignancies in cytopathology. The shortening in time required for immunopreparations and the simplification of the technique (to a few minutes and to only one step) will certainly turn this procedure into an essential tool in intraoperative cytology.

Dr. Scbmitt. The genomic profiling has been very useful to teach us about a large number of abnormalities that can be related with cell origin or biologic behavior of different tumors. However, we know that the real players are the proteins. In spite of new proteomic technologies, the ICC abnormalities reflect the presence of many acquired genetic alterations and this technique will be continue to have a very important role in guide the cytopathologist eyes.

Dr. Vielh. If appropriate controls are included and strict guidelines followed, immunocytochemistry will certainly continue to play a significant role as an adjunct technique in cytopathology. This is particularly critical when targeted therapies are planned based on the expression (ER/PR) or overexpression of certain molecules (e.g., HER2neu).

\section{D. What future advances and challenges can you predict?}

Dr. Akerman. Advances in the field include antibodies raised against gene fusion products (in diagnosis as well as prognosis), for example, Fli-1 and WT-1. Challenges include technical difficulties and aberrant expressions.

Dr. Bubendorf. The major challenge will be to standardize immunoreactions within and across laboratories.

Dr. Kapila. A challenge faced by immunocytochemistry is that even in good hands it is unpredictable on smears. Use of cell blocks has solved this problem to some extent but not completely. The procedure still needs to be standardized such that it is uniformly applicable. The future advances would be directed to identifying specific markers for different lesions and tumors. Immunostaining of cytologic specimens has not achieved a uniform level of success in the various cytology laboratories probably due to insufficient material for analysis, high background staining and difficulties in interpretation.

Dr. Katz. Antigen quantitation by imaging methods with accurate localization and quantitation of antigens to cell membrane, cytoplasm or nucleus may be important clinically.

Dr. Mulvany and Ms. Mitchell. Similar to immunohematology, ICC shares the advantages and disadvantages of any antigen-antibody reaction. Future improvements in ICC will include the use of new antibodies of both high sensitivity and specificity, algorithms for antibody panels of high discriminating value, cytoautomation, publication of practice guidelines and expansion of quality assurance programs.

Dr. Ng. Immunocytochemical study of therapeutic significance (e.g., immunostaining for EGFR, c-erbB2, hormonal receptors and c-kit) is becoming increasingly popular.

Dr. Osamura and Mr. Itob. The importance of ICC in diagnostic clinical cytology is expected to expand not only in differential diagnosis but also for therapeutic application. Future challenges lie in expansion of available tissue-specific antibodies for differential diagnosis and recruitment of the most appropriate antibodies for detection of molecular targets for the most effective treatment by humanized monoclonal antibodies or tyrosine kinase inhibitors.

Dr. Scbalper. The ever-growing increase in accuracy, costeffectiveness and possible use in exfoliative cytology will permit cytology and immunocytochemistry to reach sufficient efficiency to be used as a screening method for various cancers. Another area of development of immunocytochemistry in cytopathology is the incorporation of more and better antibodies, many of which will be important as diagnostic or prognostic 
factors in different diseases. It will also be important to define a common international nomenclature that allows us to discuss criteria and take the best out of this technique.

Dr. Schmitt. In my point of view, in the short term the greatest challenge for the use of ICC on cytologic specimens is to find a universal standardization of this technique through multi-institutional and cooperative studies. Currently, it is difficult to judge the performance of ICC in cytology, in which conditions are more erratic than in histology, and specimen processing protocols have not been well established.

Dr. Verbest. Future advances should be technical, with optimal nuclear and cytoplasmic antigen retrieval by standardized liquid-based protocols. Future challenges might be the simultaneous use of immunostain, FISH and fluorescence immunophenotyping and interphase cytogenetics as a tool for the investigation of neoplasms (m-FICTION).

Dr. Vielh. The future may be dependent on the immunodetection of a series of targets representing unique pathways of signalization specific of a given tumor. This may be derived from the ongoing progresses in proteomics and their clinical application using cytologic material.

\section{The Role of Clinical Cytogenetics}

The development of clinical cytogenetics bas paralleled the emergence of clinical cytology as a major diagnostic specialty. Clinical applications of fluorescence in situ bybridization bave been growing in the last decade.

\section{A. How often do you apply this technique?}

Dr. Akerman. In cooperation with the Department of Clinical Genetics, these techniques are applied frequently in cases of musculoskeletal tumors.

Dr. Bubendorf. Our facility applies FISH on a routine basis.

Dr. Kapila. With the advent of increasing and diverse treatment options there is a need to subclassify morphologically identical entities because this may dictate therapeutic decisions. Some tumors (e.g., rhabdomyosarcomas) undergo further testing after the initial diagnosis for identification of translocation characteristics of the alveolar variant, which modifies management.

We have limited use of this technique in our laboratory. This field has great potential and could give more specific answers than one can hope to get from immunocytochemistry, especially in cancer diagnosis and management.

Dr. Mulvany and Ms. Mitchell. Chromosomal aberrations are used most frequently for the diagnosis of lymphomas, leukemias, tumors with ambiguous ICC results and malignancies with shared cytomorphologic appearances (e.g., small round cell tumors, soft tissue tumors, etc).

Dr. Nasuti. In my practice (a major corporate references laboratory) we use FISH extensively in our urinary cytology service. Currently FISH is used in conjunction with conventional cytology and is available to our clinical clients at their request. The UroVysion product line is used in our organization. Three of the four FISH probes in the Vysis (UroVysion, Vysis/Abbott, Downers Grove, IL) UroVysion bladder cancer kit we use (CEP3-SpectrumRed, CEP7-SpectrumGreen and CEP17-SpectrumAqua) reveal duplications of chromosomes 3, 7 and 17, and the fourth probe (LSI 9p21-SpectrumGold) by its absence indicates loss of band $9 \mathrm{p} 21$. These findings in exfoliated urine cells are associated with transitional cell carcino$\mathrm{ma}$ and dysplasia, but not in reactive processes or polyoma virus infection (Figure 7). ${ }^{21,22}$ In our laboratory, FISH slides are read by dedicated technologists, with the resulting data supervised and cosigned by a supervisor with a Ph.D. This results in a fluorescence photomicrograph that is available for review by the cytotechnologist and cytopathologist at the time of sign out. The final report consisting of the microscopic diagnosis, microscopic description, FISH data and light photomicrographs is sent to clinicians via automated FAX service. The popularity of the UroVysion product line among our clinical clients has increased dramatically since its introduction in 2002 (Table I).

Dr. $\mathrm{Ng}$. Chromogenic in situ hybridization (CISH) is performed in my laboratories mainly for surgical biopsy cases of breast cancer with borderline c-erbB2 immunostaining results. However, though technically feasible, ${ }^{23} \mathrm{CISH}$ is seldom applied in FNA specimens. Occasionally, conventional cytogenetics is carried out

Table I Increased Popularity of Urine FISH Analysis

\begin{tabular}{lccc}
\hline & \multicolumn{3}{c}{ Year } \\
\cline { 2 - 4 } & $\mathbf{2 0 0 3}$ & $\mathbf{2 0 0 4}$ & $\mathbf{2 0 0 5}$ \\
\hline Total no. UCS & 108,409 & 107,106 & 101,824 \\
Total no. UCSF & 876 & 8,401 & 17,596 \\
\% UCSF & 0.81 & 7.84 & 17.28 \\
\hline
\end{tabular}

YEAR = January 1 to December 31 . Total No. UCS = total number of urine cytology specimens, Total No. UCSF = total number of urine cytology specimen with fluorescence in situ hybridization, \% UCSF = percentage of urine specimens with fluorescence in situ hybridization. 


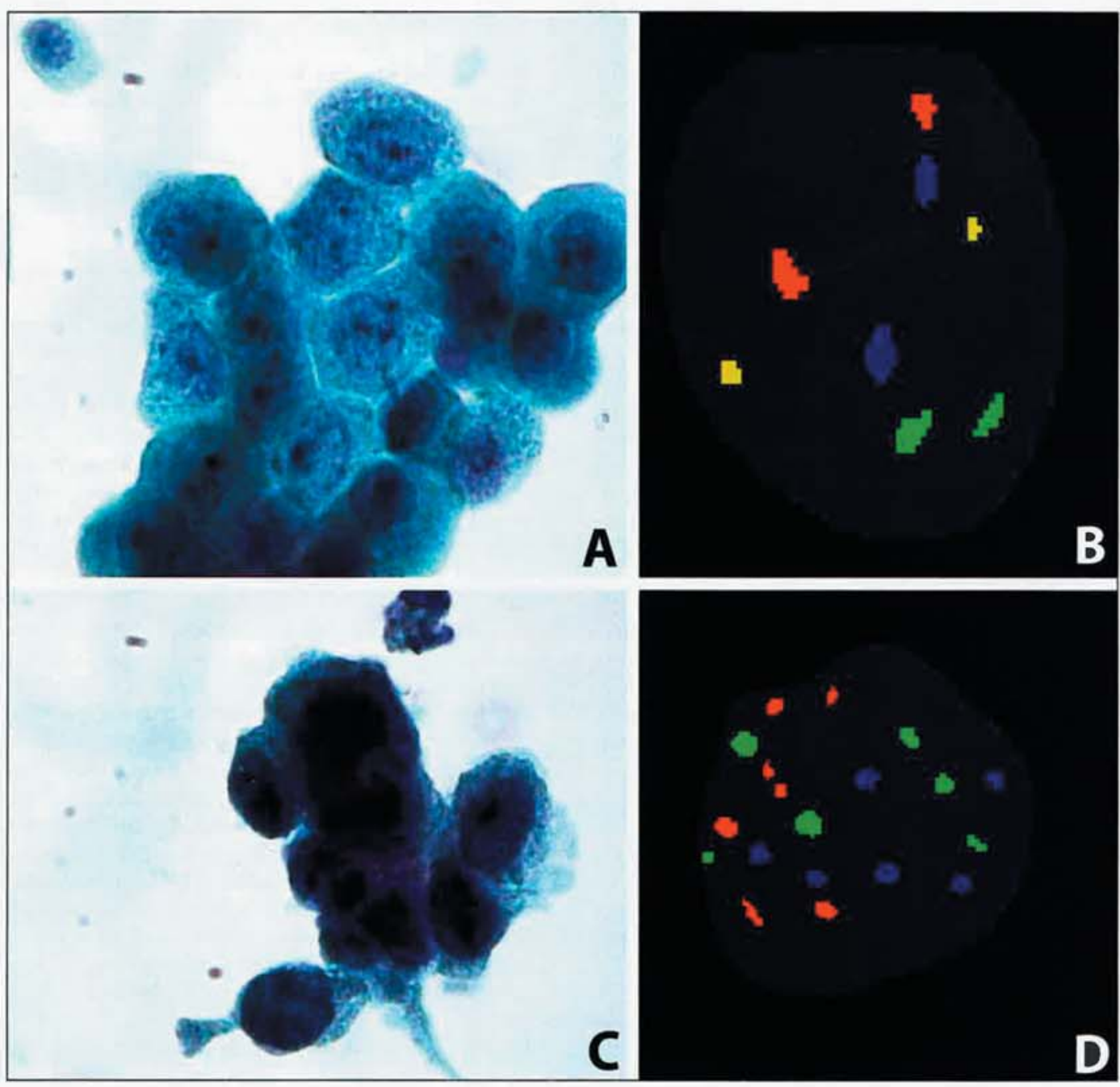

Figure 7 (A) Benign reactive urothelial tissue fragment (ThinPrep Papanicolaou stain, $\times 400$ ). (B) Corresponding negative FISH demonstrating a normal karyotype of 2 chromosome signals for 3 (red), 7 (green), 17 (aqua) and 9p21 (gold). (C) Malignant tissue fragment of transitional cell carcinoma (ThinPrep Papanicolaou stain, $\times 400$ ). (D) Corresponding positive FISH indicating an abnormal karyotype with $>2$ signals for chromosomes 3 (red), 7 (green) and 17 (aqua) and absence of a gold signal, indicating a deletion of 9p21.

using FNA samples of deep-seated pediatric solid tumors.

Dr. Schalper. We do not perform cytogenetics in our laboratory because of the high cost of implementation and restricted clinical use. Occasionally, we buy services from other centers to solve specific cases, such as autopsies of fetuses, multiple congenital malformations, atypical congenital anomalies, rare genetic syn- dromes, confirmation of presumed chromosomopathy and presence of sexual development disorder. We also use cytogenetics in some hematologic malignancies (leukemia, lymphomas and multiple myelomas) and neural tumors and for monitoring responses to medical treatments of some cancers.

Dr. Verbest. We apply cytogenetics rather rarely on cytologic material, because most patients treated in 
this cancer institute come with a diagnosis; therefore we developed PCR techniques on paraffin-embedded archival material. Our experience on floating or smeared cells is limited to oncohematology.

Dr. Vielh. Clinical cytogenetics plays a major role in academic centers devoted to the treatment of patients with malignant tumors.

\section{B. Give some examples.}

Dr. Akerman. These techniques are used frequently in small round cell malignant tumors, spindle cell sarcomas with suspicion of synovial sarcoma, suspicion of extraskeletal myxoid chondrosarcoma, and, at the Department of Clinical Cytology, for HER-2/neu amplification of breast carcinoma and SYT/SSX in suspected cases of synovial sarcoma.

Dr. Bubendorf. Most commonly, we use it in the field of urinary cytology (UroVysion), for analysis of HER2 status in breast cancer and for detection of translocations in lymphomas. Less common applications in- clude FISH to elucidate equivocal atypia in lung cytology, to ascertain the cytologic diagnosis of malignant mesothelioma and to detect specific translocations in sarcomas.

Dr. Katz. Some examples of our use of FISH are FISH probes for diagnosis of bladder cancer, for different types of lymphoma and leukemia, EGFR for lung cancer, and specific probes for chromosomal translocations for soft tissue sarcomas and small blue cell tumors and in ERB B2 for breast cancer

Dr. Mulvany and Ms. Mitchell. In FISH, centromeric probes are used mainly for the detection of polysomy (numeric chromosomal aberrations), including trisomy 12 in chronic lymphocytic leukemia, trisomy 8 in sarcoma and gain of 3, 7 and 17 in urothelial carcinoma. In contrast, locus-specific probes are mainly used for the detection of gene amplification or gene deletion, for example, in Ewing's sarcoma/ PNET $\mathrm{t}(11: 22)(\mathrm{q} 24 ; \mathrm{q} 12)$, synovial sarcoma $\mathrm{t}(\mathrm{X}: 18)$ (q11;q11), mantle cell lymphoma t(11;14) (q13:q32),

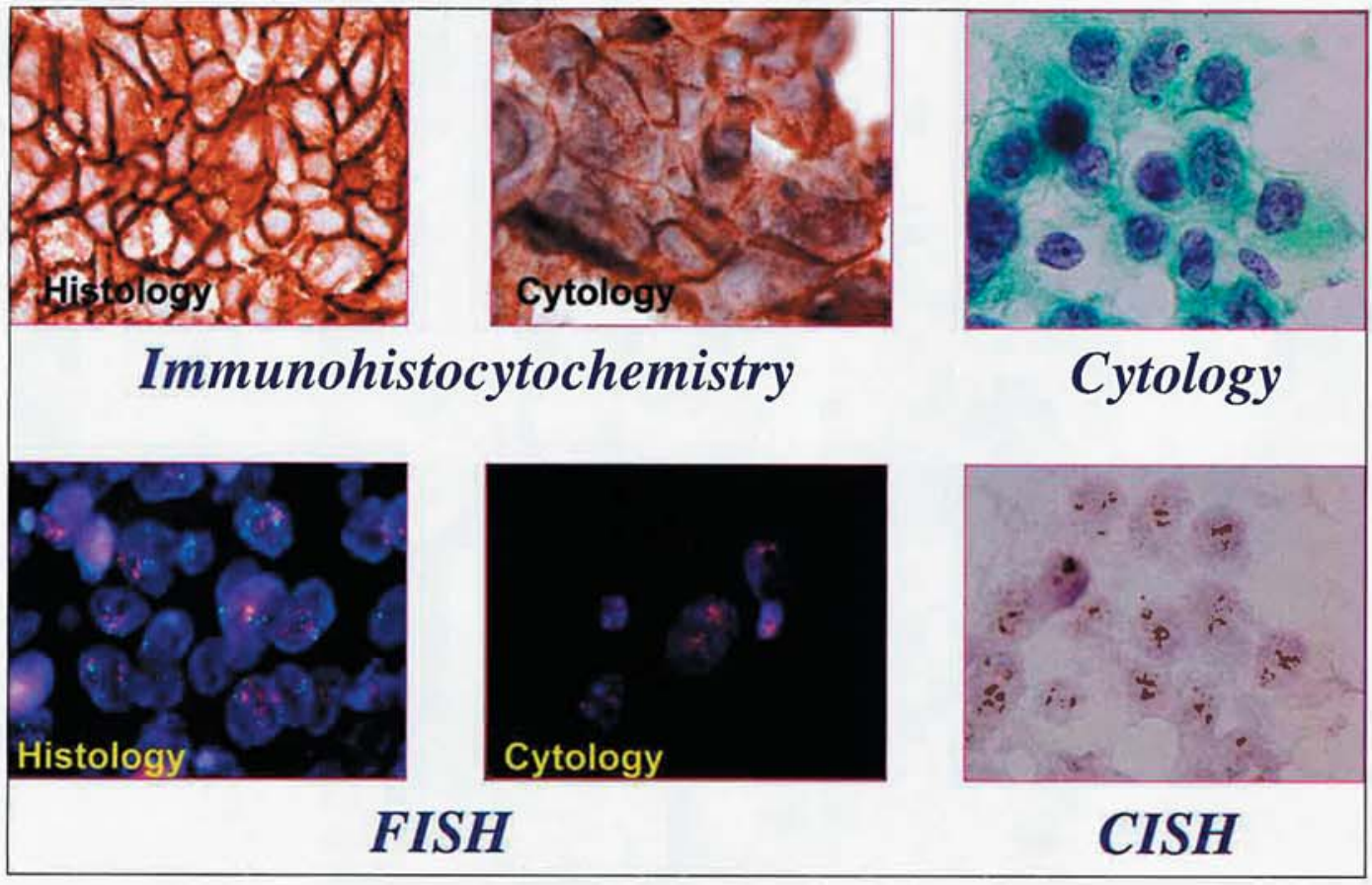

Figure 8 Immunohistocytochemistry for HER2 in breast cancer (upper left, tissue sections; upper middle, cytology). Cytology of the same cancer (left right) case (upper right). HER2 FISH for breast cancer (lower left, tissue sections; lower middle, cytology). HER2 CISH for breast cancer (lower right). 
follicular lymphomas $t(14 ; 18)(\mathrm{q} 32 ; \mathrm{q} 21)$, etc. ${ }^{24,25}$

Dr. Osamura, Mr. Itob and Mr. Serizawa. It has been claimed that approximately $15-20 \%$ of the metastatic breast cancers are HER2 FISH positive. IHC strongly positive staining for HER2 has good concordance with FISH positivity (Figure 8 ). We use Vysis PathVysion to detect HER2 amplification. The current algorithm for trastuzumab therapy for advanced and early breast cancers recommends testing by FISH only or testing by IHC and repeat IHC HE2 2+ by FISH. Thus the patients with expected response are selected. Cytologic specimen is very suitable for HER2 gene analysis.

Chromosomal translocation occurs in a tumor-specific manner and is useful in reaching a final and appropriate diagnosis, especially in sarcomas and hematologic tumors. The following are the common translocations to reach the most appropriate pathologic diagnosis in surgical pathology.
11;22 EWS-FLI1 or other ETS (ES/PNET)

11;22 EWS-WT1 (DSRCT)

X;18: SYT-SSX (synovial sarcoma)

9;22: BCR-ABL (CML, ALL)

11q23;4/9/19:MLL (ALL, AML)

15;17:PML-RARA (PML)8;14: MYC-IGH (Burkitt lymphoma)

11;14:CCND1-IGH (mantle cell lymphoma)

14;18:IGH-BCL1-2 (follicular lymphoma)

$\mathrm{t}(2 ; 5)(\mathrm{p} 23 ; \mathrm{q} 35)$ (ALCL ALK-NPM)

$\mathrm{t}(11 ; 18)(\mathrm{q} 21 ; \mathrm{q} 21)$ (MALT lymphoma)

A good example is a case of a 4-year-old boy with a mass in his neck. The differential diagnoses included extraosseous Ewing's sarcoma or desmoplastic small round cell tumor (DSRCT). FISH analysis of the tumor cells indicated the presence of "break apart" translocation of $\mathrm{t}(11 ; 22)(\mathrm{q} 24 ; \mathrm{q} 12)$, which indicated the diagnosis of Ewing's sarcoma (Figure 9). This "break apart" translocation is expected to be detected more accurately in cytologic specimens that contain
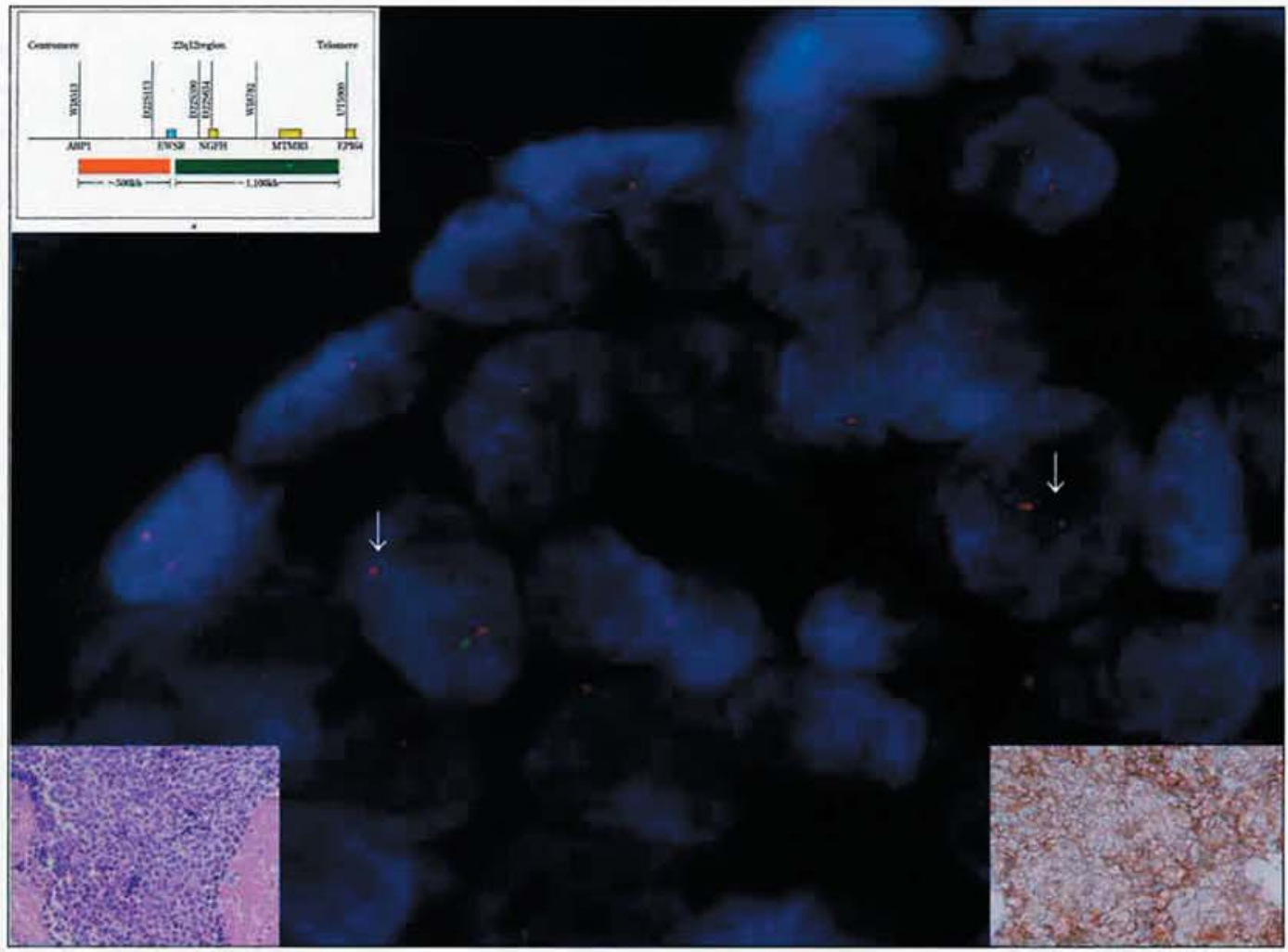

Figure 9 FISH for "break apart" translocation $\mathrm{t}(11 ; 22)(\mathrm{q} 24 ; \mathrm{q} 12)$ in a neck mass for a 4-year-old boy. $\mathrm{H}-\mathrm{E}$ staining in the lower left shows smal cell tumor. The tumor cells are immunohistochemically positive for $\mathrm{CD} 99$ (lower right). 
whole cells and whole nuclei.

Dr. Schmitt. An example for use in our facility of in situ hybridization (ISH) for HER2 is in breast samples. The clinical use of trastuzumab (Herceptin) requires evaluation of HER2 amplification on tumors from every potentially eligible patient. FISH is currently regarded as the gold standard method for detecting HER-2 amplification. The main difficulty for adopting FISH in a clinical setting is the need for additional equipment for analysis, such as fluorescence microscopy and multiband fluorescence filters. Recently, novel technology to detect DNA probes has been developed. CISH uses a simple ICC-like peroxidase reaction, and the results can be assessed using a normal light microscope. The assessment is fast, with good morphologic control, and the slides can be stored for long periods without loss of signal. Recently, many studies showed that CISH is a reliable test to assess HER2 gene copy number with an excellent correlation with FISH results (97\% for high-level amplification and $98 \%$ for normal copy number). What is the role for HER2 assessment in FNA material? In metastatic breast cancer, Herceptin is used as first-line therapy after previous chemotherapy failure. In spite of good concordance between HER2 status in primary tumors and lymph node metastasis, in distant metastases this concordance diminishes with time. So, the HER2 evaluation should be preferentially done in the metastatic tumor. Performing HER2 ICC studies on FNA material remains problematic, because HER2 scoring is not validated in this material. However, HER2 assessment using FISH or CISH is now possible and useful in FNA with excellent correlation with the histologic specimens (Figure 10). The recent ap-

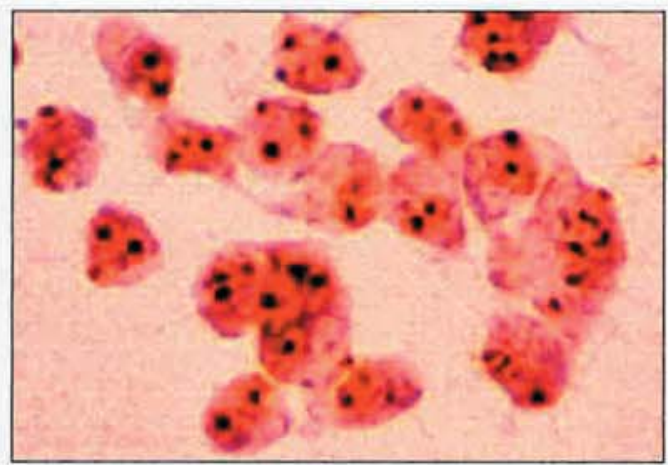

Figure 10 Alcohol-fixed smears from aspirates of metastatic breast carcinoma showing cells with increase copy number of HER2 gene detected by CISH. proval for Herceptin in adjuvant therapy can expand the use of ISH in material obtained from the primary tumor. Other examples of the use of cytogenetic techniques in our routine are identification of rare metastatic cells on effusions and study of $\mathrm{N}$-myc amplification on FNA from neuroblastomas. ${ }^{26} \mathrm{~A}$ potential and emerging field is the use of multiplex FISH for detection of recurrence of transitional carcinomas on urine specimens and for diagnosis in equivocal lung cytology. ${ }^{27}$

Dr. Verhest. Examples of application on a routine basis are dependent on the tediousness and length of the cytogenetic procedures. Metaphase cytogenetics has a high failure rate, which made FISH the preferred alternative. Aneuploidies and probe fusions or disruptions have been used in many circumstances. Specific chromosome translocations (in lymphomas and sarcomas), gene amplification (in breast cancer) and detection of rare events such as residual disease (Ewing's, neuroblastoma) benefit from interphase cytogenetics.

Dr. Vielh. For diagnosis purposes we use conventional cytogenetics, as well as detection of clonality and of specific translocation by FISH, in hematologic malignancies (lymphomas) and solid tumors (adult and childhood soft tissue tumors).

\section{C. Do you expect new probes with enhanced capabilities to emerge in cancer diagnosis?}

Dr. Alves. Clinical application of molecular probes to assess genetic alterations, such as gene amplification or tranlocations, is coming of age in some diagnostic dilemmas. Along with the confirmation of HER-2 in breast carcinomas "borderline" at ICC, the identification of translocations has become a useful tool, especially in the diagnosis of some patterns of lymphomas and particularly in sarcomas.

Dr. Bubendorf. I expect a further increase in the number of FISH probes to allow more precise diagnoses in selected fields of cytology, for example, in gynecologic or thyroid cytology. There also will be more assays to identify genetic alterations that serve as therapeutic targets.

$D r$. Katz. I expect new probes to be developed for early detection of lung cancer in sputum and for circulating tumor cells.

Dr. Schmitt. The use of large combinations of probes through the multiplex FISH technique certainly will improve the diagnostic capacity on cytologic material. Moreover, better probes to detect specific translocations will be extremely useful in the characterization 
of soft tissue tumors and malignant lymphomas in cytologic material. New genetic information are coming from the microarray technology and specific probes can be generated and used to obtain diagnostic, prognostic and predictive information on routine material. ${ }^{28}$

Dr. Verhest. FICTION is a very promising technique characterizing the basic morphology of the cell with its immunophenotypic profile and allowing simultaneous study of multiple genetic abnormalities.

The availability of many fluorescence signals with artificial colors has enhanced the possibility to widen considerably the number of probes for a comprehensive analysis of the genetic abnormalities present in individual cancer cells.

Dr. Vielh. Robust and easy to use assays applicable to cytologic material are needed to better explore the clonality of solid tumors and detect single base mutations or polymorphisms for diagnostic or therapeutic reasons.

\section{D. Cite the limitations and challenges of this technique.}

Dr. Akerman. A limitation in these techniques is that probes for FISH are still lacking for tumors with diagnostic cytogenetic markers. One of the challenges is that to ensure satisfactory, good-quality results it is necessary to use this method fairly often.

Dr. Bubendorf. FISH is often regarded as a technical, complex technology. In fact, FISH is technically straightforward and its technical complexity does not exceed the complexity of ICC. A broad and unselected application of FISH is limited by its relatively high costs. For cost calculation, not only the probes need to be considered but also the investment for a fluorescence microscope that is ideally equipped with a motorized stage for automated relocation and a camera. Given the limited resources of health systems, FISH should be applied wisely and not independently of cytomorphology. For example, FISH is useless in a urinary specimen that is positive for high-grade urothelial cancer.

Dr. Katz. I see some of the limitations and challenges being in the areas of expensive equipment, excellent quality probes, good specimen preparation and training in scoring probes.

Dr. Mulvany and Ms. Mitcbell. In the FISH probe, DNA can be labeled to identify chromosomes, regions of chromosomes or genes in order to detect ploidy, translocations, gene localization and gene amplifica- tion. ${ }^{29,30}$ In interphase FISH (iFISH), intact cells are used and time-consuming metaphase spreads can be avoided. The use of air-dried smears, alcohol-fixed slides and paraffin-embedded tissue confers great versatility to the test. The robust nature of the test and high sensitivity and specificity are limited only by the commercial probes available.

A single disease entity may not have a single pathognomonic molecular aberration and vice versa, for example, Fli-1 in Ewing's sarcoma, t(2:5)(p23:q35) in anaplastic large cell lymphoma, trisomy 12 in CLL and $\mathrm{t}(2 ; 13)(\mathrm{q} 35 ; \mathrm{q} 14)$ in alveolar rhabdomyosarcoma. Specific high-frequency chromosomal aberrations have not been discovered in most solid tumors, and in some tumors the location of the mutation is too variable for the development of a probe. However, the main deterrent to the adoption of FISH is the cost of maintaining a test with a low frequency of usage.

$\mathrm{Dr} . \mathrm{Ng}$. Evaluation of FISH requires an expensive fluorescence microscope equipped with high-quality $60 \times$ or $100 \times$ oil immersion objectives and multi-band pass fluorescence filters, which is not used in most routine diagnostic laboratories. Moreover, the fluorescence signals can fade within several weeks. The hybridization results also need to be recorded with an expensive CCD camera. Most importantly, assessment of morphology is difficult, resulting in suboptimal cytoarchitectural correlation.

CISH technology is based on single-color detection of one probe without simultaneous centromere counts. It is thus unable to evaluate numerical alterations of the chromosome studied.

In conventional cytogenetics, fresh samples in appropriate tissue culture medium are required. The procedures are also more technically demanding.

Dr. Nasuti. The major difficulty that quickly arose in our practice is what to do about a lack of correlation between FISH results and cytomorphologic findings in cases in which FISH is positive and cytology is negative or vice versa. I think that further time, experience and study will help clarify the clinical significance of a lack of correlation in such cases. For the time being, we recommend repeating the specimen in the body of the UroVysion report. Based on the current literature verifying its efficacy, our own experience and growing clinical client demand, it is obvious that diagnostic product lines such as UroVysion are here to stay.

Dr. Schalper. One of the most important challenges in cytogenetic in the near future is making major progress in identification of clinically useful alterations in solid tumors. Possibly the most important variants of the FISH technology, comparative genom- 
ic hybridization (CGH), multicolor karyotyping and interphase FISH will help in this task. ${ }^{31}$ In addition, we hope that the automatization of equipment and globalization of new cytogenetic proof will reduce the complexity and cost of these examinations.

Dr. Schmitt. CISH and FISH have emerged as reliable techniques to identify amplifications and chromosomal translocations. $\mathrm{CISH}$ provides a spatial distribution of gene copy number changes in tumor tissue and allows a direct correlation between copy number changes and the morphologic features of neoplastic cells. However, the limited number of commercially available gene probes has hindered the use of CISH. One of the big challenges of the technique is to generate probes for CISH that can be applied in routine cytologic material. Recently our group devised a protocol to generate probes for CISH that can be applied to formalin-fixed, paraffin-embedded tissue sections (FFPETS). ${ }^{32}$ Bacterial artificial chromosomes (BACs) containing fragments of human DNA that map to specific genomic regions of interest are amplified with phi 29 polymerase and random primer labeled with biotin. The genomic location of these can be readily confirmed by BAC end pair sequencing and FISH mapping on normal lymphocyte metaphase spreads. This protocol enables the generation of probes mapping to any gene of interest that can be applied to FFPETS, allowing correlation of morphologic features with gene copy number.

Dr. Verbest. The first limitation is the need to localize the chromosome rearrangements of potential diagnostic and prognostic relevance and determine the locus of the affected genes on the karyotype before synthesizing new probes. The challenge is to make digital imaging analysis less expensive.

Dr. Vielb. One of the current limitations of the FISH technique is the difficulty to use, in a single assay, a very large cocktail of probes, each probe being tagged with a different fluorochrome. Other limitations include the exact quantitation of the fluorescent signal, even though new automatic devices seeming to fulfill the gap are currently developed and evaluated, and the comparison between fluorescent signals with morphology. Among the future anticipated challenges are the development of new in situ techniques able to quantitate the expression of mRNA and to detect single base alterations of diagnostic and of therapeutic interest without the need of nucleic acid extraction.

\section{E. Can you forecast where the field is going?}

Dr. Akerman. This field can be expected to expand, with development of further probes for FISH, espe- cially prognostic.

Dr. Bubendorf. FISH is going to expand in histology and cytology, and an increasing number of laboratories will adopt this technology. A minimum throughput is required to justify the investment and retain expertise in technology and evaluation. Thus, small cytology laboratories should seek collaboration with specialized FISH facilities. There will be increased automatization in technical procedure and evaluation, allowing improved standardization and minimizing interobserver variability. For example, high-end image analysis systems for automated analysis of multitarget FISH in urinary cytology and HER-2 FISH have become commercially available.

Dr. Katz. The field is moving in the area of automation of FISH counting, with specialized fluorescent microscopes and multiple filters for multiprobe FISH with four colors becoming the norm. Many more FISH tests will be developed and used frequently, for example, EGFR for lung cancer, VHL for renal cell carcinoma and probes for early detection of lung cancer.

Dr. Mulvany and Ms. Mitcbell. Interphase chromogenic in situ hybridization (iCISH) combines the convenience of ICC with the advantages of iFISH. This technique allows the use of routine diagnostic material, bright-field microscopy and direct correlation with cytomorphologic appearances on the Papanicolaoustained slides. Different translocations can be simultaneously visualized using chromogens of different colors. With iCISH the slides are also archivable and provide a permanent record. ${ }^{33}$

Dr. Ng. These technologies are developing as adjunct investigations in diagnosis of certain tumors with distinctive cytogenetic abnormalities (such as lymphoma, synovial sarcoma or renal cell carcinoma), ${ }^{34}$ as well as determination of targeted therapy. ${ }^{23,35}$ FISH and CISH, whether applied in surgical biopsies or cytology specimens, have the potential to replace conventional cytogenetics in the future.

Dr. Scbalper. Therefore it is possible that in the following years the use of cytogenetics may extend to detection, diagnosis, and prognosis and selection of molecular therapeutic targets for various malignancies.

Dr. Scbmitt. The value of cytology specimens cannot be limited to the analysis of individual markers or genetic alterations. CGH is a molecular cytogenetic method that allows scanning of the entire genome in a tumor sample and thus provides an overview of DNA 
sequence copy number changes. At variance with other cytogenetic techniques, cell culture or fresh or frozen tissue is not required. Recently, it was demonstrated that CGH may be successfully performed on DNA extracted from cytologic material. ${ }^{28}$ Most important, as a significant amount of data on chromosomal gains and losses have been described by means of $\mathrm{CGH}$ in virtually every human malignancy, $\mathrm{CGH}$ and array-based CGH may in the near future be used for refinement of cytologic diagnosis in difficult cases. By defining the regions of gains and losses, less complex methods such as CISH or loss of heterozygosity $(\mathrm{LOH})$ could be used for increasing diagnostic accuracy. mRNA is more unstable than DNA, and mRNA levels may change in different environments and under harsh conditions; thus it is yet to be determined if cytologic samples can be used for cDNA arrays experiments and whether $\mathrm{cDNA}$ arrays will contribute to cytologic diagnosis of malignant tumors. Notwithstanding these limitations, FNA may eventually become the ideal method in determining the adequacy of a given tumor for high-throughput studies.

Dr. Verbest. Multiple FICTION has been developed in the field of lymphoid neoplasms. Future uses for this sophisticated FISH technique are in the extended applications with dedicated probes for analysis of solid tumors, micrometastases and residual disease.

More simple and cost efficient is the use of nonspecific centromeric probes to detect aneuploidies, clues of malignancy in the differential diagnosis of reactive vs. cancer cells. For example, FISH of voided urine sediment is a sensitive and specific test used for the detection of urothelial carcinoma. The technique is also applied in effusions or in the evaluation of treatment in patients with leptomeningeal metastases and is beginning to be complementary to conventional cytology.

Dr. Vielh. The field is moving to a more integrated approach combining the power of molecular techniques to detect specific events with classic morphology.

\section{The Role of Molecular Techniques}

Molecular techniques are becoming important adjuncts to cytology for tumor diagnosis and prognosis. PCR-based assays for oncogene mutations and amplifications bave potential applications in cytology. A variety of molecular assays for oncogene activation (RAS, BRAF, KIT, EGFR), tumor suppressor gene expression loss (p53), DNA instability (microsatellite analysis) and other forms of molecular testing bave demonstrated clinical utility in cytology.

\section{A. Name a few applications of this technology presently used in your clinical setting.}

Dr. Akerman. In cooperation with the Departments of Clinical Genetics, our facility uses this technology in diagnosis of malignant small round cell sarcoma and synovial sarcoma. We use multiplex PCR (FTA Micro Card, Whatman BioScience, Newton Center, Massachusetts, U.S.A.) for diagnosing monclonality and Tcell lineage in aspirates from suspected nonHodgkin's lymphoma. ${ }^{36}$

Dr. Alves. Point mutations and even gene expression profiles are now detectable in cytologic samples. As an example, in several centers, including ours, advances in the diagnosis of follicular lesions of thyroid are promising diagnostic tools. Another instance is the search for molecular alterations yielding identification of the neoplastic nature of cells from metastatic breast cancer in effusion.

Dr. Bubendorf. Applications in our routine diagnostics include EFGR sequence analysis in non-small cel lung cancer and multiplex PCR for analysis of clonality and translocations in lymphomas. We use regular Papanicolaou-stained specimens for these analyses.

Dr. Kapila. We are not using this in our laboratory. However, it is used in our department in tissues of patients with carcinoma of the colon and papillary carcinoma of the thyroid.

Dr. Katz. We presently use very few molecular techniques in our practice. We occasionally get a request for mutation analysis for EGFR. Nuclear matrix protein testing can be performed on urine and is used at the bedside by clinicians and although cheaper, may not be as accurate as diagnosing the presence of urothelial carcinoma by FISH. The use of PCR to diagnose $T$ cell receptor genes in low-grade peripheral T cell lymphomas may be occasionally required; however, the vast majority of lymphomas are successfully immunophenotyped and assigned clonality by flow cytometry or cytospin inmunocytochemistry. The use of ZAP 70 by flow cytometry correlates with unmutated IgVH genes and more rapid disease progression in CLL/SLL, and if the assay is performed appropriately, may be substituted for PCR-based analysis of immunoglobulin genes.

Dr. Mulvany and Ms. Mitchell. Molecular techniques are used to identify those early genetic changes that offer some advantage for cell survival or growth and hence are conserved. The advantages may be due to activation of oncogenes, for example, RAS, BRAF, KIT, EGFR, N-myc in neuroblastoma or inactivation of tumor suppressor genes, such as $\mathrm{p} 53(7 \mathrm{p} 31.1)$, and RB. ${ }^{37}$ Oncogene activation may be achieved by translocation, point mutation or amplification, and all 
lead to increased gene expression. In contrast, inactivation of tumor suppressor genes may be accomplished by physical loss, missense or truncating gene mutations and all result in loss of an allele ( $\mathrm{LOH})$.

$D r$. Nasuti. In our reference laboratory, with the exceptions of DNA human papillomavirus (HPV) hybrid capture on liquid-based Papanicolaou smears and FISH on urine specimens, we do not currently use molecular techniques in our daily cytology practice. This will most probably change in the near future due to increasing demand by our clinical clients for data on activation of oncogenes such as RAS, BRAF, KIT and EGFR or loss of tumor gene suppressors such as $\mathrm{p} 53$, especially since knowledge of molecular status of a given tumor has often resulted in diagnostic, prognostic and therapeutic implications for cancer patients. The success of providing such information by PCRbased assays on a scale of a commercial laboratory will of course depend on several factors. Included among these is the ability of the assay to be performed efficiently and reliably on the typically scant amount of cellular material derived from FNA procedures. Equally as important is the economic feasibility of having at the ready the hardware, reagents and trained personnel needed to perform sophisticated assays such as PCR. I am confident that as was the case with DNA hybrid capture and FISH, other ancillary studies based on molecular techniques will rapidly emerge that will meet all necessary criteria for its regular utilization in high-volume reference laboratories.

Dr. $\mathrm{Ng}$. ISH for Epstein-Barr virus (EBV)-encoded RNA (EBER) is used in our facility for confirming diagnosis of metastatic nasopharyngeal carcinoma in lymph node FNA. Reverse transcriptase (RT)-PCR is used for demonstrating $t(x, 18)$ in soft tissue FNA for synovial sarcoma. PCR-based immunoglobulin heavy chain gene rearrangement study or $\mathrm{T}$ cell receptor gene rearrangement study are used for confirming monoclonal B or T cell proliferations in lymph node FNA for non-Hodgkin's lymphoma. PCR-based DNA amplification is used for diagnosing mycobacterial infection in lymph node FNA for tuberculous lymphadenitis. PCR-based DNA amplification and DNA sequencing are used for demonstrating EGFR, c-kit or platelet-derived growth factor receptor-alpha mutations in both surgical biopsies and FNA samples.

Dr. Osamura, Mr. Itob and Mr. Serizawa. The molecular techniques that have been applied to the clinical cytology include ISH (to detect DNA) and FISH. The former is most well represented by the detection of specific DNA typing for HPV. FISH has been actively applied in detecting gene amplification, translocation and deletion. The cytologic specimens are suit-

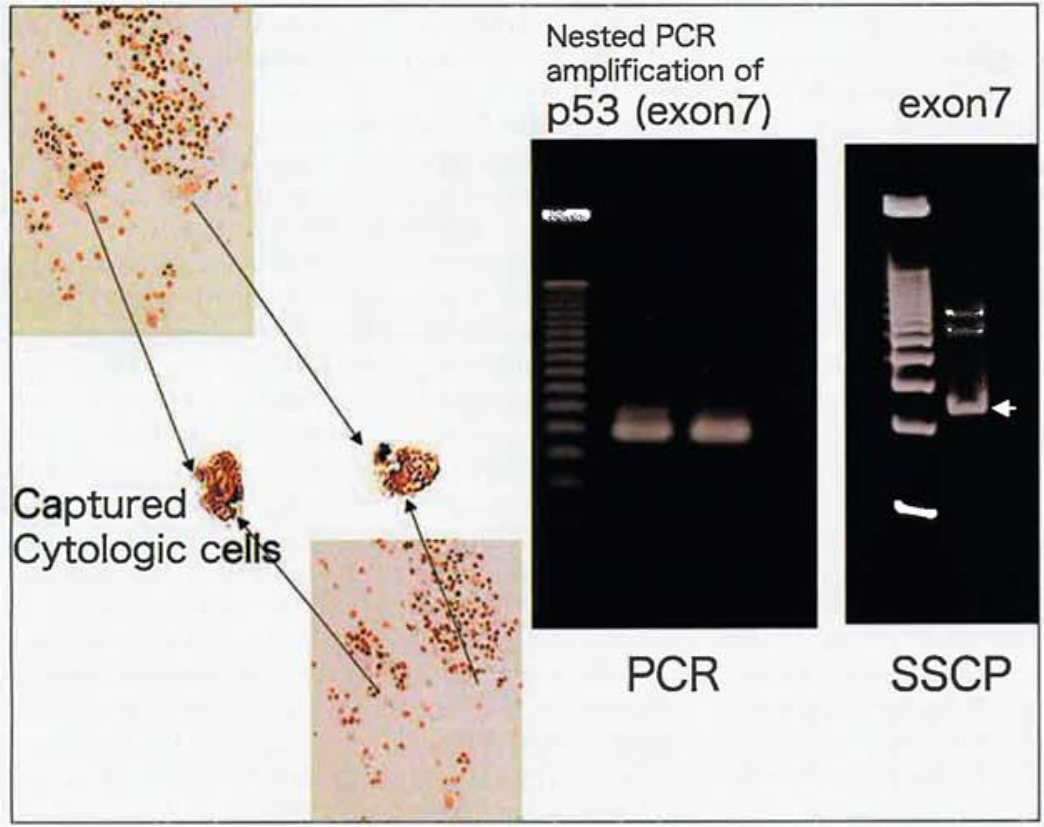

Figure 11 Laser capture microdissection (LCM) assisted mutation analysis for $\mathrm{p} 53$ in the breast cancer smear. A cluster of the cancer cells was dissected (arows) and was subjected to PCR and SSCP for exon7. Direct sequencing was subsequently done. 
able for FISH technique. The other useful technique efficiently applied to cytologic specimens is laser capture microdissection (LCM). The dissected DNA or RNA can be subjected to PCR-SSCP-DNA sequencing and RT-PCR to detect trivial amounts of RNA.

Ethanol-fixed cytologic specimens are suitable for the molecular detection of DNA and RNA, as well as for FISH. It is expected that the ethanol-fixed cytologic specimens yield a larger amount and higher quality of DNA and RNA sequences. We perform FISH techniques to demonstrate amplification and translocation, usually using commercially available kits such as Vysis PathVysion or Ventana Imform.

Recently introduced CISH also has been applied to the cytology specimens.

Laser capture microdissection (LCM) is an efficient method for combining morphology examination and gene analysis. LCM can select particular cells from which DNA or RNA is extracted. DNA is then subjected to PCR and SSCP, followed by sequence analysis. This is illustrated by a case of breast carcinoma whose cancer cells on the cytology specimens were selected by LCM and subjected to PCR, SSCP and subsequent direct sequencing (Figure 11). This tumor showed the presence of point mutation at exon 7, which is a "hot spot" on the p53 gene.

Dr. Schalper. The molecular biology techniques used in our clinical settings are PCR, hybrid capture and FISH. PCR is used mainly to detect and typify certain microorganisms through identification of their genetic material (e.g., human papillomavirus [HPV], Mycobacterium tuberculosis, Pneumocystis carinii [jiroveci], etc.) and to determine clonal rearrangements in lymphomas. We use hybrid capture for detection and serotipification of HPV in gynecologic cytology. ${ }^{38}$

Dr. Schmitt. We currently use molecular analysis for detection of KIT mutations on GISTs diagnosed by endoscopic ultrasound-guided $\mathrm{FNA},{ }^{39}$ molecular analysis for detection of EGFR mutations or amplification in metaplastic breast carcinoma and lung nonsmall cell carcinomas, ${ }^{40,41}$ and $\mathrm{LOH}$ for detection of metastatic disease in pleural effusions from breast cancer patients.

Dr. Verbest. We use the PCR technique on paraffinembedded tissue for the detection of $\mathrm{IgH}$ and IGK in the differential diagnosis of $\mathrm{B}$ cell lymphomas and the presence of their specific translocation and for $\mathrm{T}$ cell lymphomas for the TCR $\gamma$ gene rearrangement. Chromosome translocations in myxoid liposarcoma, synovial sarcoma and Ewing's tumor are also studied by reverse-transcriptase (RT)-PCR for detection of their fusion transcript.
Dr. Vielh. We use PCR-based techniques of clonality detection for the diagnosis of some lymphomas, as well as for detecting translocations or gene amplification of diagnostic or of prognostic interest in some solid adult and childhood tumors.

\section{B. Will targeted therapies boost the use of molecular techniques in cytology?}

Dr. Akerman. In skilled hands, FNA is probably an excellent sampling technique to use when the efficacy of such a treatment is investigated.

Dr. Bubendorf. Undoubtedly, targeted therapies will boost the use of molecular techniques in both histopathology and cytology.

Dr. Katz. As in the case of FISH tests, if there is a good molecular marker that correlates with response to therapy, it will be requested.

Dr. Mulvany and Ms. Mitchell. Since specific molecular testing is a prerequisite for many targeted therapies, there is little doubt but that the development of molecular studies will increase. ${ }^{42}$

Dr. Scbalper. The directed molecular treatments and massive data analysis strategies will have a strong impact on the utilization of molecular techniques in cytology. Soon it will not be enough to state only the morphologic characterization and the immunocytochemistry of certain anomalies. Instead, it will be necessary to have precise molecular data in order to choose the adequate treatment for each condition.

Dr. Schmitt. Definitively! As more molecular targets for therapy are identified, cytopathologists will be increasingly called upon to help identify patients who are suitable candidates for therapeutic agents that target such molecules, and the practice of pharmacopathology will assume increasing importance. Recently, our group demonstrated the feasibility of performing ICC and molecular analysis of c-kit and PDGFRA genes in cytologic material obtained by endoscopic ultrasound-guided FNA from GISTs (Figure 12).39 This procedure allows a more precise diagnosis and therapeutic decision in the routine management of patients with GISTs. The same was demonstrated for EGFR in non-small cell lung cancer. ${ }^{41}$ Recently the feasibility of studying EGFR mutations was demonstrated using the nested PCR technique to predict response to gefinitib in lung cytologic material. Amplification of the EGFR gene is also associated with resistance to therapy in some cases. EGFR amplification was detected by CISH in $30 \%$ of cases of metaplastic breast carcinomas. ${ }^{40}$ Given that these tumors 


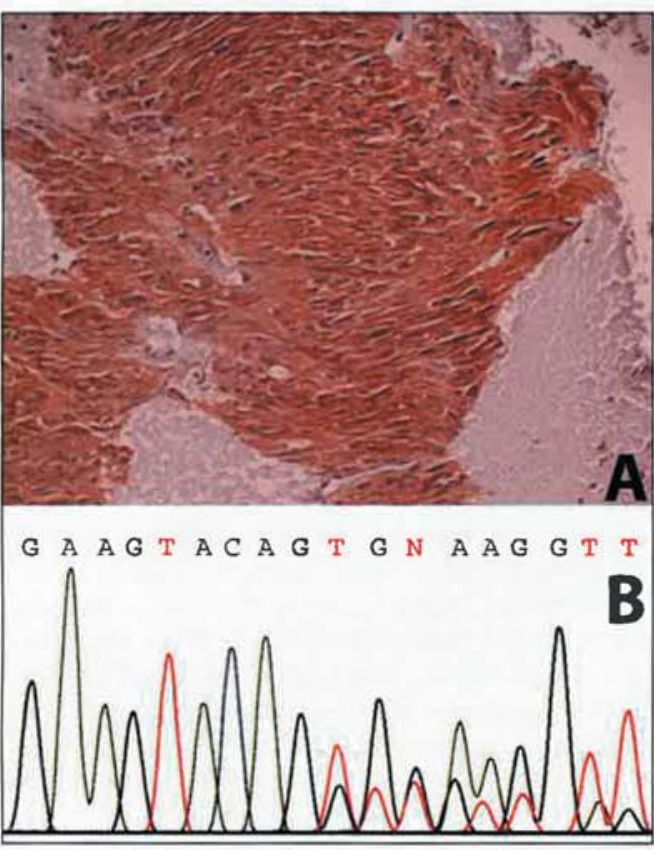

Figure 12 GIST diagnosed by FNA. (A) See the strong immunostaining for C-Kit. (B) Observe the mutation in the exon 11 of C-Kit gene, deletion of codons 557 and 558.

are resistant to conventional chemotherapy and hormone therapy regimens, our findings indicate that studies are warranted to explore EGFR TK-inhibitors as potential therapeutic agents for metaplastic breast carcinomas (MBCs) harboring amplifications of EGFR.

Dr. Verbest. The success of targeted therapies on tumors rely on the demonstration by immunostaining of the transcripts from oncogene activation of EGFR, for example, c-Kit. This approach is still feasible in a cytopathology department. But other methods such as microarrays, PCR amplification and direct sequencing, high-resolution melting analysis will be tested for clinical practice in laboratories of molecular biology working in translational collaborations. These developments will be the privilege of some university hospitals funded by research grants in rich countries and remain outside the daily routine of the cytologist working in the outback of the "global village."

Dr. Vielh. Targeted therapies will definitively boost the use of these techniques in cytology, especially if cytopathologists implement these tools in their arma- mentarium.

\section{C. Can you foresee the advances and challenges?}

Dr. Akerman. Some lesions and tumors are difficult to aspirate. The technique used must be able to function with small amounts of tumor tissue, and aspirates must be sufficient for at least a control smear and the molecular testing.

Dr. Alves. Whenever necessary, the use of ICC and other molecular tools will progressively be added for a more detailed diagnosis, prognostic assessment and therapeutic selection. It must be stressed, however, that these new molecular tools will be clinically useful only when applied in samples adequately collected and preserved, complementing the most detailed cytomorphologic approach.

Dr. Bubendorf. The variable mixture of tumor cells and normal cells is a major challenge when it comes to the molecular analysis of diagnostic or therapeutic targets in cytologic specimens. For in situ analyses (e.g., by FISH), automated relocation is required in case of specimens with rare tumor cells. Similarly, laser microdissection is often needed to purify the cancer cell populations on diagnostic specimens for subsequent PCR analysis. PCR and subsequent DNA sequence analysis can be achieved in as few as 30 microdissected cells. It is important that we cytologists take an active role in the adoption and application of molecular techniques, since we are able to interpret the results in the light of cytomorphology. If we do not act, others will take over.

Dr. Colgan. The advance of molecular techniques poses two challenges for the cytology laboratory: deciding when to adopt a new test and deciding who should perform and interpret it. Deciding to adopt a new test is often the result of a dynamic between the laboratory and its clients and patients. On the one hand, it can be expected that there will be pressure on cytology laboratories from clinicians, patients and the health care industry to rapidly adopt new molecular techniques for prognostication and therapy, often even before there is a sufficient level of evidence of demonstrated efficacy. Consequently, the cytology laboratory will likely find itself squeezed between rising expectations for advances in molecular medicine and the limitations imposed by good evidence-based practice and funding. The cytopathology laboratory that is thoughtful and deliberate in its implementation of new molecular techniques may face irritated clinicians and the movement of specimens or referrals to boutique, esoteric testing laboratories.

The second major challenge for the cytology labo- 
ratory in the implementation of molecular testing is designating who is capable of performing the requisite molecular techniques and interpreting the actual test results. Either cytotechnologists must acquire an additional and recognized skill set for different, molecular techniques, or the testing must be performed by other properly trained and duly recognized technologists. In some jurisdictions, the personnel responsible for the performance of new molecular techniques will be determined by practice standards or regulations. In the United States, some schools of cytotechnology are reforming their curricula and degrees to meet this new challenge. Certainly, cytotechnologists cannot assume that all techniques for assessing cells, that is, "cytology," will remain within their own practice scope indefinitely! Second, the final cytopathology report must provide a synthesis of morphology and molecular testing. Cytopathologists must be comfortable not only with morphology but also molecular diagnostic interpretation.

Dr. Kapila. I personally think this field is challenging and has great potential in tumor diagnosis and management. However, in spite of its increasing role in diagnostics, a morphologic basis would still be required.

Molecular techniques are likely to transform cancer diagnosis and management. Molecular analysis of tumor nucleic acid will help in prediction, classification and therapy of cancer. An integrated molecular diagnostic service to be shared by various disciplines would be ideal. Traditional cytopathology training with molecular expertise and liaison of specialized laboratories would be the need for the future.

Dr. Katz. I do not believe that the cytopathologist will be performing molecular tests; however, we will be procurers of tissue, by FNA or other methods, to send to a laboratory for testing. Our role will be to submit representative tissue for the molecular assay. I foresee, however, that there will be a large role for microarray chips customized per disease state, for either diagnosis or prognosis.

Dr. Mulvany and Ms. Mitchell. Twenty-five years after its discovery, recombinant DNA technology is offering practical solutions to diagnostic problems in microbiology and hematology. However, its adoption by the cytology fraternity has been slow in spite of the publication of numerous articles in the cytopathology journals.

FNA is an ideal source of material for molecular studies. Compared to paraffin-embedded tissue it offers the advantages of disaggregated, intact cells. For the patient, the advantages include low cost, prompt access and the avoidance of surgery. The coupling of
FNA with molecular biology, particularly the newer techniques, offers new horizons. Tissue microarray facilitates high-throughput molecular profiling of cells for DNA, RNA or protein targets. ${ }^{43,44}$ Other developments include multiplex PCR, DNA chip technology, laser-assisted microdissection, microsatellite analysis, proteomics and microarray-based comparative genomic hybridization. 45,46 Currently, in situ detection of single base mutations, such as mutant KRAS for pancreatobiliary carcinoma, is confined to the research laboratory.

PCR allows specific amplification of target nucleic acid sequences. It shares the same versatility of specimen sample as FISH but has a greater number of technical disadvantages. These include contamination, pseudoclones giving false positive results and the need for thermocycling. In some instances the analytic sensitivity of PCR may be as low as $45 \%$ due to scattering of breakpoints during translocation. Since the newer tests do not require nucleic acid extraction, PCR may well be superseded. Furthermore, when specific molecular abnormalities are detected in any specimen it may be difficult to decide whether these represent the presence of a nonvisualized malignancy or merely an unstable epithelium capable of being primed for malignant transformation.

In the future, most if not all tumor diagnoses will consist of a morphologic type with molecular subclassification. Malignant lymphoma serves as a striking example. Candidate markers are presently being assessed not only for detection of disease but also to determine prognosis and response to specific treatment. Common sense dictates that molecular classification alone will never suffice and validation by a second and independent process such as cytomorphology will continue to be mandatory. ${ }^{47}$

Dr. Ng. When applying molecular technologies, FNA sometimes has advantages over core biopsy, because there are fewer problems associated with tumor cell homogenization. DNA microarray technology is gaining popularity as an investigative tool for both diagnosis and determination of tumor prognosis (as in diffuse large B cell lymphoma). ${ }^{48,49}$

On the other hand, molecular biology results are meaningful only if interpreted with proper morphologic correlation. Thus a close collaboration between anatomic pathologists (including cytopathologists) and molecular biologists is essential for providing high-standard diagnostic services.

More organized and systematic molecular biology training is required in both undergraduate and postgraduate pathology education. Standardization of molecular technologies is a major concern in ensuring the quality of diagnostic services. Enrollment in good in- 
terlaboratory comparison schemes or external proficiency testing programs is thus essential.

Dr. Osamura, Mr. Itoh and Mr. Serizawa. The future challenges of the molecular techniques include how to contribute to early diagnosis of cancer, how to perform the tests for molecular profiles in the metastatic carcinoma and how to use appropriate molecular technologies to select patients for more effective targeted molecular therapy.

It can be well anticipated that the demand of the molecular techniques will be expanded and will become more popular technologies among the cytopatholgists and cytotechnologists.

Dr. Schalper. One of the main challenges of molecular biology in the coming years will be the incorporation of the necessary strategies to demonstrate its applicability and validity and to recognize its true uses and limitations. However, the high cost of these techniques and the complexity of the data obtained from them will limit for some time the speed of expansion and accumulation of experience in this field. It seems necessary to incorporate new paradigms that fit better in the complexity of many of the new systems for analysis and information. It also seems necessary to incorporate the emerging language for characterizing in a more precise way the biologic structures, such as fractal geometry for sinuous and irregular surfaces and fractal mathematics for dynamic and nonlinear behavior, ${ }^{50-52}$ as well as to understand the biologic entities as complex adaptive systems. ${ }^{53}$

It is exciting to think that in the more distant future, the use of nanotechnology (miniaturization), robotics and virtual microscopy will allow us to do virtual, in vivo, in situ, morphologic, functional and remote cytodiagnosis, in which micro-equipment will be ingested or introduced into a duct or blood vessel and guided by virtual imaging ${ }^{54}$ to detect a lesion, fix on it, stain it and micro-manipulate it to make the diagnosis and perform the treatment of the illness.

Dr. Scbmitt. Although molecular techniques are used for the diagnosis and prognosis of several types of diseases, most frequently we applied these techniques for cancer diagnosis, prognosis and therapeutic indications. It is very difficult to predict the progress that should be anticipated over the next $10-50$ years, because cancer is such a complex problem, with hundreds of forms and diverse means of controlling them. However, with the continued aging of the population the absolute number of cancer diagnoses will very likely rise substantially in the coming decades. So, for the foreseeable future, we will need better ways to diagnose and treat cancers, especially the solid tumors of breast, lung, colon, prostate, ovary and other organs, that are common in older age-groups. In terms of therapy, from a practical standpoint for the pathologist, it will be mandatory to have tumor cells available from patients participating in clinical trials in order to study the molecular features that correlate with sensitivity or resistance to the cancer drug targets. ${ }^{55}$ The availability of tissues or cells may allow retrospective identification of a molecular profile or surrogate marker characteristic of responding tumors, even when the demonstration of activity is limited to a small group of patients (e.g., EGFR alterations in subsets of breast carcinomas). In turn, this profile or marker could be used prospectively for patient enrollment in subsequent studies with selected patients. At the time of tumor progression, one could also consider assessment of newly acquired genetic alterations to select the next line of therapy.

FNA offers a suitable alternative to biopsy in a variety of clinical settings in which it may be useful to obtain material to study prognostic and predictive markers. Many studies have shown the possibility of using FNA to study response to therapy and evaluation of morphologic changes of tumor cells with minimal discomfort for the patients. However, because therapies are now being directed toward individual molecular targets, the big challenge for the use of cytologic technology is a need for increased standardization of preanalytical and analytical methods. Cytology as a medical specialty also calls for changes. These include stronger working relationships between cytopathologists and bench scientists, between cytopathologists in academia and those in community hospitals and between cytopathologists and other physicians and new training programs that provide opportunity to understand and accelerate education on use of the tools we have and incorporate new technologies into these processes.

Dr. Vielh. We foresee the advances of these technologies as an adjunct to morphology through the use of dedicated microarrays, allowing a global and integrative approach depending on the question asked (diagnosis, prognosis, prediction of treatment response), for example, $\mathrm{CGH}$ array for exploring the entire genome of a given tumor, expression profiling for measuring differential mRNA expression levels and detection of specific mutations in a known gene. Considering the small amount of DNA and RNA obtained using FNA, implementation of robust and reliable protocols to linearly amplify nucleic acid will be required.

\section{Concluding Remarks}

Dr. Bibbo. I would like to thank all the participants 
for their contribution to this symposium. I am certain that our readers will enjoy as much as I did looking over the horizon with our expert participants and discovering how new technologies are reshaping the practice of nongynecologic cytology.

The response of the participants reflects a variety of approaches in their clinical settings and personal opinions. Worthy of mention is the remarkable uniformity of the views expressed by the participants on the role of morphology 10 years from now: the practice of diagnostic cytopathology will continue to grow, and new technologies will not replace morphologic features but rather serve as adjunct tools. It is no surprise that guided FNA is performed more often by radiologists, although pathologists, clinicians, and surgeons also perform the procedure. Most participants agreed that core biopsies can also be obtained when FNA is performed in cases of soft tissue tumors, bone tumors and breast, prostate and liver lesions. Technical advances in imaging will create greater opportunities for cytopathologists, and the sophistication of equipment will expand the use and safety of FNA according to most. A variety of preparations were recommended for immunocytochemistry of cytologic specimens but paraffin-embedded cell block was preferred by many. The importance of immunocytochemistry will grow and continue to play an important role as an adjunct technique, but the need to establish standardized processing protocols is an important point. As expected, FISH applications have been on the rise, as shown in various examples in urinary cytology, breast cancer and detection of translocations in soft tissue sarcomas. Mentioned difficulties include lack of correlation between FISH positive results and negative cytology and vice versa, the generation of probes for $\mathrm{CISH}$ that can be applied to routine cytologic samples and automation of FISH counting. The emphasis on caution is particularly important in that molecular techniques will be used with increasing frequency as adjuncts to cytology for tumor diagnosis and prognosis and pressure will be exerted on laboratories to implement these techniques. The challenge as pointed out is deciding when to adopt a new molecular test and who should perform and interpret it. Since molecular biology results are meaningful only when interpreted with proper morphologic correlation, it is important to standardize molecular techniques and organize education in molecular biology for pathologists.

\section{References}

1. Willén H, Ảkerman M: Fine needle aspiration of nodular fasciitis: No need for surgery. Acta Orthop Scand (suppl 265) 1995; 66:54-55

2. Virchow RR: Cellular Pathology. London, Churchill, 1860

3. Koss LG: Aspiration biopsy, cytologic interpretation and histo- logic basis. Tokyo, Isaku Shoin, 1992

4. Schmitt FC: Thyroid cytology: FNA is still the best diagnostic approach. Cytopathology 2006;17:210-216

5. Domanski H A, Åkerman M, Carlen B, Engellau J, Gustafson P, Jonsson K, Mertens F, Rydholm A: Core-ncedle biopsy performed by the cytopathologist: A technique to complement fine-needle aspiration of soft tissue and bone lesions. Cancer 2005;105:229-239

6. Nasuti JF, Gupta PK, Baloch ZW: Diagnostic value and costeffectiveness of on-site evaluation of fine-needle aspiration specimens: Review of 5,688 cases. Diagn Cytopathol 2002;27: $1-4$

7. Cobb CJ, Raza AS: Alas poor FNA of breast-We knew thee well! Diagn Cytopathol 2005:32:1-4

8. Terzakis JA: X-ray microanalysis: Problem solving in surgical pathology. Pathol Annu 1985;2059-81

9. Fadda G, Rossi ED, Mule A, Miraglia A, Vecchio FM, Capelli A: Diagnostic efficacy of immunocytochemistry on fine needle aspiration biopsies processed by thin-layer cytology. Acta Cytol 2006;50:129-135

10. Baloch ZW, Lee A, Cobbs C, Roberts S, LiVolsi VA, Gupta PK: Millipore filter cell block preparation: An alternative to cell block in non-gynecologic specimens of limited cellularity. Diagn Cytopathol 1999;20:389-392

11. Osamura R, Watanabe K, Akatsuka Y: Peroxidase-labeled antibody staining for carcinoembryonic antigen of cytologic specimens for light and electron microscopy. Acta Cytol 1985;29; 254-256

12. Afify AM, al-Khafaji BM: Diagnostic utility of thyroid transcription factor-1 expression in adenocarcinomas presenting in serous fluids. Acta Cytol 2002;46:675-678

13. Bibbo M: Comprehensive Cytopathology. Second edition, Philadelphia, WB Saunders, 1997

14. Flens MJ, van der Valk P, Tadema TM, Hysmans AC, Risse EK, van Tol GA, Meijer CI: The contribution of immunocytochemistry in diagnostic cytology: Comparison and evaluation with immunohistology. Cancer Cytopathol 1990;65:2704-2711

15. Åkerman M, Ryd W, Skytting B: Fine needle aspiration of synovial sarcoma: Criteria for diagnosis: Retrospective re-examination of 37 cases, including ancillary diagnosis. A Scandinavian Sarcoma Group study. Diagn Cytopathol 2003;28:232-238

16. Coindre JM: Immunohistochemistry in the diagnosis of soft tissue tumours. Histopathology 2003;43:1-16

17. Reis-Filho IS, Milanezi F, Amendoeira I, Albergaria A, Schmitt FC: Distribution of p63, a novel myepithelial marker, in fineneedle aspiration biopsies of the breast. Cancer Cytopathol 2003;99:172-179

18. Åkerman M, Domanski HA: Fine needle aspiration (FNA) of bone tumours: With special emphasis on definitive treatment of primary malignant bone tumours based on FNA. Curr Diagn Pathol 1998;5:82-92

19. Kirkegaard T, Edwards J, Tovey S, McGlynn LM, Krishna SN, Mukherjee R, Tam L, Munro AF, Dunne B, Bartlett JM: Observer variation in immunohistochemical analysis of protein expression: Time for a change? Histopathol 2006;48:787-794

20. Rudiger T, Hofler H, Kreipe HH, Nizze H, Pfeifer U, Stein H, Dallenbach FE, Fischer HP, Mengel M, von Wasieleski R, Muller-Hermelink HK: Quality assurance in immunohistochemistry: Results of an interlaboratory trial involving 172 pathologists. Am J Surg Pathol 2002;26:873-882

21. Sarosdy MF, Schellhammer P, Bokinsky G, Kahn P, Chao R, 
Yore L, Zadra J, Burzon D, Osher G, Bridge JA, Anderson S, Johansson SL, Lieber M, Soloway M, Flom K: Clinical evaluation of a multi-target fluorescent in situ hybridization assay for detection of bladder cancer. Urology 2002;168:1950-1954

22. Veeramachaneni R, Nordberg ML, Shi R, Herrera GA, Turbat-Herrera EA: Evaluation of fluorescence in situ hybridization as an ancillary tool to urine cytology in diagnosing urothelial carcinoma. Diagn Cytopathol 2003;28:301-307

23. Lin F, Shen T, Prichard JW: Detection of HER-2/neu oncogene in breast carcinoma by chromogenic in situ hybridization in cytologic specimens. Diagn Cytopathol 2005;33:376-380

24. Speicher MR, Carter NP: The new cytogenetics: Blurring the boundaries with molecular biology. Nat Rev Genet 2005;6: $782-792$

25. Caraway NP: Strategies to diagnose lymphoproliferative disorders by fine-needle aspiration by using ancillary studies. Cancer Cytopathol 2005:105;432-442

26. Ross FM: The impact of cytogenetics on lymphoma diagnosis. Curr Diagn Pathol 2004:10;345-350

27. Barroca H, Carvalho IL, Gil da Costa MI, Cirnes L, Seruca R, Schmitt FC: Detection of N-myc amplification in neuroblastomas using Southern blotting on fine needle aspirates. Acta Cytol 2001;45:169-172

28. Savic S, Glatz K, Schoenegg R, Spieler P, Feichter G, Tamm $\mathrm{M}$, Bubendorf L: Multitarget fluorescence in situ hybridization elucidates equivocal lung cytology. Chest 2006;129:1629-1635

29. Oliveira MA, French CA: Applications of fluorescence in situ hybridization in cytopathology: A review, Acta Cytol 2005;49: 587-594

30. Wolman SR: Applications of fluorescence in situ hybridization techniques in cytopathology. Cancer Cytopathol 1997:81:193197

31. Reis-Filho JS, Schmitt FC: Fluorescence in situ hybridization, comparative genomic hybridization, and other molecular biology techniques in the analysis of effusions. Diagn Cytopathol 2005;33:294-299

32. Lambros MBK, Simpson PT, Jones C, Natrajan R, Westbury C, Steele D, Savage K, Mackay A, Schmitt FC, Ashworth A, Reis-Filho JS: Unlocking pathology archives for molecular genetic studies: A reliable method to generate probes for chromogenic and fluorescent in situ hybridization. Lab Invest 2006;86:398-408

33. Tanner M, Gancberg D, Di Leo A, Larsimont D, Ruuas G, Piccart MJ, Isola J: Chromogenic in situ hybridization: A practical alternative for fluorescence in situ hybridization to detect HER-2/neu oncogene amplification in archival breast cancer samples. Am J Pathol 2000:157;1467-1472

34. Kishimoto K, Kitamura T, Fujita K, Tate G, Mitsuya T: Cytologic differential diagnosis of follicular lymphoma grades 1 and 2 from reactive follicular hyperplasia: Cytologic features of fine-needle aspiration smears with Pap stain and fluorescence in situ hybridization analysis to detect $\mathrm{t}(14 ; 18)(\mathrm{q} 32 ; \mathrm{q} 21)$ chromosomal translocation. Diagn Cytopathol 2006;34:11-17

35. Klijanienko J, Couturier J, Galut M, El-Naggar AK, Maciorowski Z, Padoy E, Mosseri V, Vielh P: Detection and quantitation by fluorescence in situ hybridization (FISH) and image analysis of HER-2/neu gene amplification in breast cancer fineneedle samples. Cancer 1999;87:312-318

36. Dictor $\mathrm{M}$, Warenholt J, Isinger A: Resolving T-cell receptor clonality in two and genotype in four multiplex polymerase chain reactions. Hematologia 2005;90:1524-1532
37. Leong A SY, Robbins P, Spagnolo DV: Tumor genes and their proteins in cytologic and surgical specimens: Relevance and detection systems. Diagn Cytopathol 1995;13:411-422

38. Rimm DL: Molecular biology in cytopathology: Current applications and future directions. Cancer 2000;90:1-9

39. Gomes, AL, Bardales R, Milanezi F, Reis R, Schmitt F: Molecular analysis of Kit and PDGFRA in GISTs diagnosed by EUS. Am J Clin Pathol 2006 (in press)

40. Reis-Filho JS, Milanezi F, Carvalho S, Simpson PT, Steele D, Savage K, Lambros MBK, Pereira E, Nesland J, Lakhani SR, Schmitt FC: Metaplastic breast carcinomas exhibit EGFR, but not HER2, gene amplification and overexpression: Immunohistochemical and chromogenic in situ hybridization analysis. Breast Cancer Res 2005;7:R1028-R1035

41. Shih JY, Gow CH, Yu CJ, Yang CH, Chang YL, Tsai MF, Hsu YC, Chen KY, Su WP, Yang PC: Epidermal growth factor receptor mutations in needle biopsy/aspiration samples predict response to gefitinib therapy and survival of patients with advanced nonsmall cell lung cancer. Int J Cancer 2006;118:963969

42. Dietel M, Sers C: Personalized medicine and development of targeted therapies: The upcoming challenge for diagnostic molecular pathology: A review. Virchows Arch 2006;448:744-755

43. Moch H, Kononen J, Kallioniemi OP, Sauter G: Tissue microarrays: What will they bring to molecular and anatomic pathology? Adv Anatomic Pathol 2001;8:14-20

44. Schneider V: Tissue microarrays for testing molecular biomarkers of cervical intraepithelial neoplasia: Feasibility study. Acta Cytol 2006:50:123-128

45. El-Naggar A: Methods in molecular surgical pathology. Semin Diagn Pathol 2002;19:56-71

46. Rimm DL: Molecular biology in cytopathology: Current applications and future directions. Cancer Cytopathol 2000:90;1-9

47. Golub TR, Slonim DK, Tamayo P, Huard C, Gaasenbeek M, Mesirov JP, Coller H, Loh ML, Downing JR, Caligiuri MA, Bloomfield CD: Molecular classification of cancer: Class discovery and class prediction by gene expression monitoring. Science 1999;286:531-537

48. Alizadeh AA, Eisen MB, Davis RE, Ma C, Lossos IS, Rosenwald A, Boldrick JC, Sabet H, Tran T, YuX, Powell JI, Yang L, Marti GE, Moore T, Hudson J Jr, Lu L, Lewis DB, Tibshirani R, Sherlock G, Chan WC, Greiner TC, Weisenburger DD, Armitage JO, Warnke R, Levy R, Wilson W, Grever MR, Byrd JC, Botstein D, Brown PO, Staudt LM: Distinct types of diffuse large B-cell lymphoma identified by gene expression profiling. Nature 2000;403:503-511

49. Goy A, Stewart J, Barkoh BA, Remache YK, Katz R, Sneige N, Gilles F: The feasibility of gene expression profiling generated in fine-needle aspiration specimens from patients with follicular lymphoma and diffuse large B-cell lymphoma. Cancer 2006;108:10-20

50. Briggs J: Fractals: The Patterns of Chaos. Touchstone, 1992

51. Prigogine Y: Order Out of Chaos. New York, Bantam, 1984

52. Stewart I: The Mathematic of Chaos. Cambridge, Massachusetts, Blackwell, 1990

53. Lewin R: Complexity. Second edition. Tusquets, 2002

54. Bradbury J: Journey to the centre of the body. Lancet 2000;356: 2074

55. Varmus H: The new era in cancer research. Science 2006;312: 1162-1165 


\section{Suggested Reading}

Camargo RYA, Longatto Filho A, Alves VAF, Bisi H, Kanamura CT, Abelin NMA: Lactoferrin in thyroid lesions: Immunoreactivity in fine needle aspiration biopsy samples. Acta Cytol 1996;40: 408-413

Granja NM, Soares R, Rocha S, Paredes I, Longatto Filho A, Alves VA, Wiley E, Schmitt FC, Bedrossian C: Evaluation of breast cancer metastases in pleural effusions by molecular biology techniques. Diagn Cytopathol 2002;27:210-213

Longatto Filho A, Bisi H, Alves VAF, Kanamura CT, Oyafuso MS, Bortolan J, Lombardo V: Adenocarcinoma in females detected in serous effusions. Acta Cytol 1997;41:961-971
Longatto Filho A, Alves VAF, Kanamura CT, Nonogaki S, Bortolan J, Lombardo V, Bisi H: Identification of the primary site of metastatic adenocarcinoma in serous effusions: Value of an immunocytochemical panel added to the clinical arsenal. Acta Cytol 2002;46:651-658

Mitteldorf CATS, Alves VAF, Kanamura CT, Carneiro PC: Immuno-cytochemistry applied to aspiration biopsy cytology: Diagnostic contribution in 100 cases of previously stained, routine specimens. Acta Cytol 1999;42:218-226

Nascimento MC, Bisi H, Alves VA, Longatto-Filho A, Kanamura CT, Medeiros-Neto G: Differential reactivity for galectin-3 in Hürthle cell adenomas and carcinomas. Endocr Pathol 2001;12 275-279 


\section{References}

1 Bibbo M: How technology is reshaping the practice of nongynecologic cytology: frontiers of cytology symposium. Acta Cytol 2007;51: 123-152.

2 Syrjanen K: Sixty Years of Acta Cytologica. Acta Cytol 2017;61:1-2.

3 Roy-Chowdhuri S, Goswami RS, Chen H, Patel KP, Routbort MJ, Singh RR, et al: Factors affecting the success of next-generation sequencing in cytology specimens. Cancer $\mathrm{Cy}-$ topathol 2015;123:659-668.

4 Marinsek ZP, Nolde N, Skelin IK, Nizzoli R, Onal B, Rezanko T, et al: Multinational study of oestrogen and progesterone receptor immunocytochemistry on breast carcinoma fine needle aspirates. Cytopathol 2013;24:7-20.

5 Nobre AR, Albergaria A, Schmitt F: p40: A p63 isoform useful for lung cancer diagnosis - a review of the physiological and pathological role of p63. Acta Cytol 2013;57:1-8.

6 Selinger CI, Li BT, Pavkalis N, Links M, Gill AJ, Lee A, et al: Screening for ROS1 gene rearrangements in non-small-cell lung cancers using immunohistochemistry with FISH confirmation is an effective method to identify this rare target. Histopathology 2017;70:402411.
7 Miki Y, Neat M, Chandra A: Application of the Paris System to atypical urine cytology samples: correlation with histology and UroVysion FISH. Cytopathology 2017;28: 88-95.

8 Flores-Staino C, Darai-Ramqvist E, Dobra K, Hjerpe A: Adaptation of a commercial fluorescent in situ hybridization test to the diagnosis of malignant cells in effusions. Lung Cancer 2010;68:39-43.

9 Dudley JC, Zheng Z, McDonald T, Le LP, Dias-Santagata D, Borger D, et al: Next-generation sequencing and fluorescence in situ hybridization have comparable performance characteristics in the analysis of pancreaticobiliary brushings for malignancy. J Mol Diagn 2016;18:124-130

10 Lorito Di A, Schmitt F: (Cyto)Pathology and sequencing: next (or last) generation? Diagn Cytopathol 2011;40:459-461.
11 Travis WD, Brambilla E, Noguchi M, Nicholson AG, Geisinger KR, Yatabe Y, et al: International Association for the Study of Lung Cancer/American Thoracic Society/European Respiratory Society International Multidisciplinary Classification of Lung Adenocarcinoma. J Thorac Oncol 2011;6:244-285.

12 Bernadt CT, Collins BT: Fine-needle aspiration biopsy of HPV-related squamous cell carcinoma of the head and neck: current ancillary testing methods for determining HPV status. Diagn Cytopathol 2017;45:221-229.

13 Schmitt FC: Molecular cytopathology and flow cytometry: pre-analytical procedures matter. Cytopathology 2011;22:355-357.

14 Malapelle U, de Las Casas CM, Molina M, Rosell R, Spasenija S, Bihl M, et al: Consistency and reproducibility of next-generation sequencing and other multigene mutational assays: a worldwide ring trial study on quantitative cytological molecular reference specimens. Cancer 2017, DOI: 10.1002/cncy.21868.

15 Longatto-Filho A, Schmitt FC: Cytology education in the 21st century: living in the past or crossing the rubicon? Acta Cytol 2010;54: 654-656. 